PNL-7562

UC-702

05.7

\title{
Simulation of Unsaturated Flow and Solute Transport at the Las Cruces Trench Site Using the PORFLO-3 Computer Code
}

M. L. Rockhold

S. K. Wurstner

March 1991

Prepared for the U.S. Department of Energy under Contract DE-AC06-76RLO 1830

Pacific Northwest Laboratory Operated for the U.S. Department of Energy by Battelle Memorial Institute 


\title{
DISCLAIMER
}

This report was prepared as an account of work sponsored by an agency of the United States Government. Neither the United States Government nor any agency thereof, nor Battelle Memorial Institute, nor any of their employees, makes any warranty, expressed or implied, or assumes any legal liability or responsibility for the accuracy, completeness, or usefulness of any information, apparatus, product, or process disclosed, or represents that its use would not infringe privately owned rights. Reference herein to any specific commercial product, process, or service by trade name, trademark, manufacturer, or otherwise does not necessarily constitute or imply its endorsement, recommendation, or favoring by the United States Government or any agency thereof, or Battelle Memorial Institute. The views and opinions of authors expressed herein do not necessarily st ate or reflect those of the United States Government or any agency thereof.

\author{
PACIFIC NORTHWEST LABORATORY \\ operated by \\ BATTELLE MEMORIAL INSTITUTE \\ for the \\ UNITED STATES DEPARTMENT OF ENERGY \\ under Contract DE-ACO6-76RLO 1830
}

Printed in the United States of Amerita

Ayailable to DOE and DOE contractors frum the

Office of Scientific and Jechnical information, P.O. Box 62, Oak Ridge, IN 37831;

prices available from (615) 576-8401. FTS 626-8401.

Available to the public irom the National Technical Information Service, U.S. Department of Commerce, 528S Port Royal Rd., Springfield, VA 22161. 
PNL-7562

UC-702

SIMULATION OF UNSATURATED FLOW AND SOLUTE TRANSPORT AT THE LAS CRUCES TRENCH SITE USING THE PORFLO-3 COMPUTER CODE

M. L. Rockhold

S. K. Wurstner

March 1991

Prepared for

the U.S. Department of Energy

under Contract DE-ACO6-76RLO 1830

Pacific Northwest Laboratory

Richland, Hashington 99352 


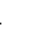




\section{SUMMARY}

The objective of this work was to test the ability of the PORFLO-3(a) computer code to simulate water infiltration and solute transport in dry soils. Data from a field-scale unsaturated zone flow and transport experiment, conducted near Las Cruces, New Mexico, were used for model validation. A spatial moment analysis was used to provide a quantitative basis for comparing the mean simulated and observed flow behavior.

The scope of this work was limited to two-dimensional simulations of the second experiment at the Las Cruces trench site. Three simulation cases are presented. The first case represents a uniform soil profile, with homogeneous, isotropic hydraulic and transport properties. The second and third cases represent single stochastic realizations of randomly heterogeneous hydraulic conductivity fields, generated from the cumulative probability distribution of the measured data.

Two-dimensional simulations produced water content changes that matched the observed data reasonably well. Models that explicitly incorporated heterogeneous hydraulic conductivity fields reproduced the characteristics of the observed data somewhat better than a uniform, homogeneous model. Improved predictions of water content changes at specific spatial locations were obtained by adjusting the soil hydraulic properties (i.e., calibrating the model).

Only fair agreement between the simulated and observed solute concentrations was obtained. Although the field experiment was specifically designed to create a two-dimensional flow regime, underprediction of the observed peak tritium concentrations appeared to be the result of threedimensional flow and edge effects that resulted from natural soil heterogeneity and from the solution samplers being too close to the face of the trench.

A significant finding of this work was the relatively poor mass balance that was obtained using the head-based form of the flow equation with the standard Picard iteration method that is employed in the PORFLO-3 code.

(a) PORFLO-3 is copyrighted by Analytic and Computational Research, Inc., subject to Limited Government License. 
This poor mass balance motivated the development of a new version of the code that uses a mixed form of the flow equation with a modified Picard iteration method. This formulation reduced the cumulative mass balance error for the 277-day simulations, from an average of $6.3 \%$ of the water mass added, to within machine precision (effectively perfect mass balance) for the same problem, with no more computational effort. This suggests that the modified Picard iteration method will improve the accuracy of the PORFLO-3 code for solving highly nonlinear unsaturated flow and transport problems.

The lack of spatial resolution of solute concentration measurements and apparent edge effects limited the usefulness of the second Las Cruces trench experiment as a rigorous validation test of the transport simulation capabilities of the PORFLO-3 code. In addition, certain aspects of the site were ignored in the model simulations, such as the spatial correlation of soil hydraulic properties. Therefore, the results of this study should only be considered a qualitative validation of the PORFLO-3 code. However, the results of this study demonstrate the importance of site-specific data for model calibration. Applications of the code for waste management and remediation activities will require site-specific data for model calibration before defensible predictions of unsaturated flow and contaminant transport can be made. 


\section{ACKNOWLEDGMENTS}

This study was conducted by the Pacific Northwest Laboratory (PNL) under the auspices of the Hanford Site Performance Assessment Program. We would like to thank Dr. M. J. Fayer of PNL for reviewing this work, and express our appreciation to Dr. J. B. Kool of HydroGeologic, Inc., Herndon, Virginia, for providing the subroutine used for estimating spatial moments. Computational support on the Hanford Cray X-MP/18 computer was provided by the Environmental Division of Westinghouse Hanford Company, Richland, Washington. 


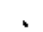

,

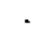

' 
CONTENTS

SUMMARY .................................

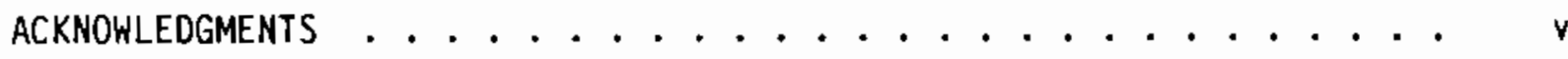

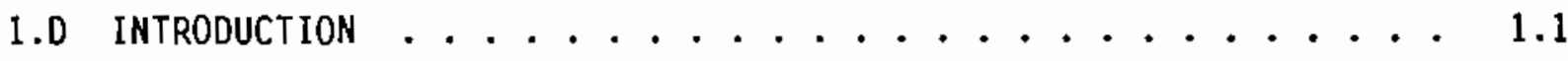

2.0 SITE AND EXPERIMENTAL PLOT DESCRIPTION . . . . . . . . 2.1

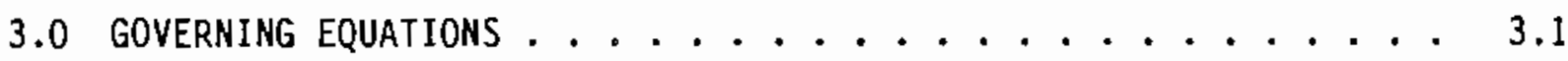

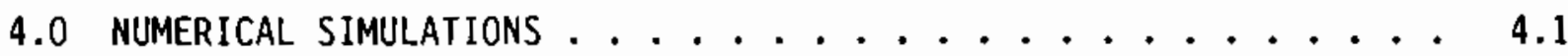

4.1 MODELING SCENARIOS . . . . . . . . . . 4.1

4.2 INITIAL AND BOUNDARY CONDITIONS ............ 4.2

4.3 flow AND TRANSPORT PARAMETERS . . . . . . . . . . 4.4

4.4 SPATIAL MOMENT ANALYSIS . . . . . . . . . . . . 4.8

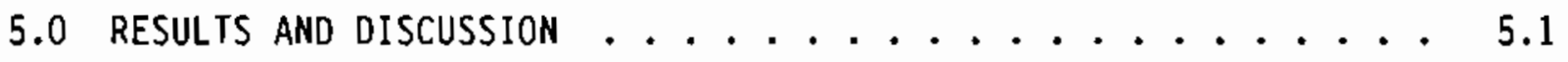

5.1 FIELD OBSERVATIONS . . . . . . . . . . . . . 5.1

5.2 SimUlatiON RESULTS . . . . . . . . . . . . 5.7

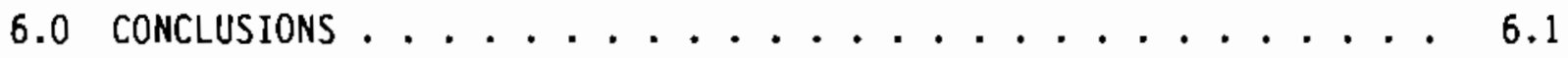

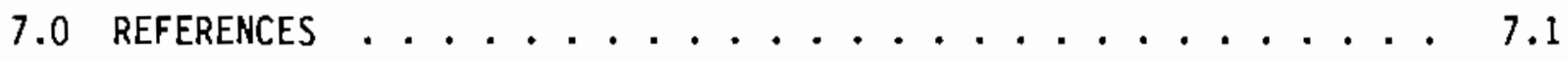

APPENDIX - THE STANDARD AND MODIFIED PICARD ITERATION METHODS . . . A.I 


\section{FIGURES}

2.1 Plan View of the Jornada Trench Experimental Site . . . . . 2.2

2.2 Location of Solution Samplers and Tensiometers for Plot $2 \ldots 2.3$

4.1 Initial Water Content Profiles Used for Model Simulations . . 4.4

4.2 Water Retention Curves Used for Model Simulations . . . . . 4.7

4.3 Cumulative Probability Distribution of Saturated Hydraulic Conductivities .................. 4.8

5.1 Observed Initial Water Content for Transects 1, 2, and 3... 5.2

5.2 Observed Water Content Changes for Transect 1 for

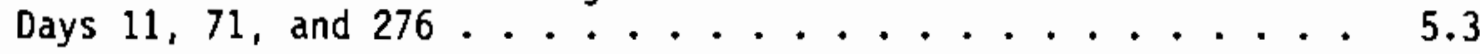

5.3 Observed Water Content Changes for Transect 2 for Days 11,71 , and $276 \ldots \ldots \ldots . \ldots . \ldots . \ldots$

5.4 Observed Water Content Changes for Transect 3 for

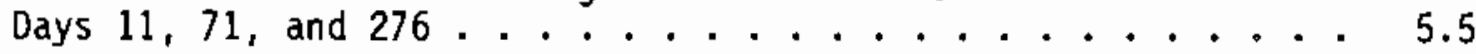

5.5 Observed Relative Tritium Concentrations for

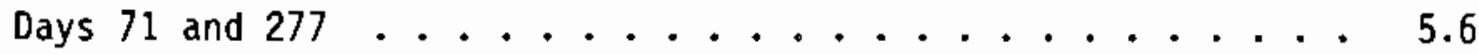

5.6 Simulated water Content Changes from Case 1 for Days 11,71, and 277 .................... 5.8

5.7 Simulated Relative Tritium Concentrations from Case 1 for Days 71 and 277 . . . . . . . . . . .

5.8 Simulated Water Content Changes from Case 2 for

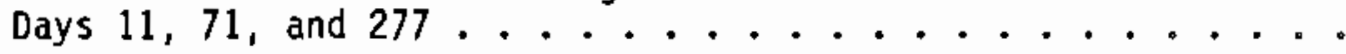

5.9 Simulated Relative Tritium Concentrations from Case 2 for Days 71 and $277 \ldots \ldots \ldots \ldots$

5.10 Simulated Water Content Changes from Case 3 for Days 11, 71, and $277 \ldots \ldots \ldots \ldots$

5.11 Simulated Relative Tritium Concentrations from Case 3 for Days 71 and 277 . . . . . . . . . . . 


\section{$\underline{\text { TABLES }}$}

4.1 Hydraulic Parameter Estimates for the Las Cruces Trench Site . . 4.5

4.2 Hydraulic Parameters Used in Model Simulations . . . . . . . . 4.6

5.1 Normalized Spatial Moments of Observed and Simulated Water Plumes on Days 11, 71, and 277 . . . . . . . . . 5.15 


\subsection{INTROOUCTIDN}

Development of waste management strategies and remediation techniques requires the use of computer models to predict the fate of contaminants introduced into the subsurface. One such computer model in use at the Hanford Site is PORFLO-3(a) (Runchal and Sagar 1989; Sagar and Runchal 1990). PORFLO-3 is a deterministic, single-phase computer code designed to simulate fluid flow, heat transfer, and mass transport in three-dimensional, variably saturated, heterogeneous, and anisotropic geologic media. Before defensible predictions of unsaturated flow and contaminant transport can be made with PORFLO-3, it should be thoroughly tested, for anticipated scenarios, to ensure that it provides reasonably accurate results.

Testing of computer models is usually divided into three categories: 1) verification, 2) benchmarking, and 3) validation. Verification is usually accomplished by comparing model results against selected analytical solutions. This comparison tests the effects of temporal and spatial discretizations and other assumptions made for obtaining the numerical solution. Benchmarking consists of comparing the output of a code to the output produced by other independently developed codes for the same problem. This provides a check on the correctness of the code Togic. Version 1.0 of PORFLO-3 has recently been subjected to independent verification and benchmarking (Magnusen et al. 1990).

Although verification and benchmark tests are important, they do not necessarily establish that a computer model provides a reasonable approximation of reality. Such assurance is only provided by comparing model results with the results from controlled experiments or observations. This latter aspect is sometimes referred to as validation and is the subject of this report. Even when models can be shown to provide a correct representation of the processes or systems for which they are intended, validation may ultimately depend on direct calibration of models using site-specific data.

Accurate and reliable predictions of water flow and contaminant transport in the unsaturated zone may be compromised by computational difficulties in

(a) PORFLO-3 is copyrighted by Analytic and Computational Research, Inc., subject to Limited Government License. 
solving the nonlinear governing equations and by difficulties in obtaining required model calibration data. Calibration data are particularly important because of the natural heterogeneity of most geologic media. The inability of many deterministic models to adequately represent and account for spatial variability and parameter uncertainty has led to the development of stochastic methods for simulating unsaturated flow and transport (Polmann et al. 1988).

As part of a comprehensive field study designed to provide validation data sets for testing stochastic and deterministic models of unsaturated flow and transport, the U.S. Nuclear Regulatory Commission (NRC) has funded several infiltration experiments in the semiarid region of New Mexico. These experiments have been conducted by personnel at New Mexico State University, Las Cruces, New Mexico. The experiments provide detailed data on hydraulic properties and water and chemical movement through initialiy dry, spatially variable soil.

The objective of this report is to document the ability of the PORFLO-3 computer code to simulate field-scale unsaturated flow and transport processes at the Las Cruces trench site. Data from the second NRC infiltration experiment conducted at the site were used for model validation. This work was conducted by Pacific Northwest Laboratory(a) for the U.S. Department of Energy.

This report is organized into seven sections. Section 2.0 gives a brief description of the Las Cruces trench site and experimental plots. Section 3.0 describes the governing equations used for modeling unsaturated flow and solute transport. Section 4.0 describes the simulations and spatial moment analyses. Section 5.0 summarizes the field observations and simulation results. Section 6.0 presents the conclusions. Section 7.0 lists the references cited in this report. The appendix provides a description of an improved numerical scheme for maintaining mass balance when simulating unsaturated flow.

(a) Pacific Northwest Laboratory is operated for the U. S. Department of Energy by Battelle Memorial Institute. 


\subsection{SITE AND EXPERIMENTAL PLOT DESCRIPTION}

The experimental site is located approximately $40 \mathrm{~km}$ northeast of Las Cruces, New Mexico. According to Wierenga (1988), the climate, geology, geomorphology, soil, and vegetation in the vicinity of the field site are similar to many arid and semiarid areas of the southwestern United States. The average annual precipitation is $23 \mathrm{~cm}$, with $52 \%$ occurring between July and the end of September. The average Class A pan evaporation rate is $239 \mathrm{~cm} / \mathrm{yr}$.

A 26.4-m-long by 4.8-m-wide by 6.0 -m-deep trench was excavated in undisturbed soil to provide samples for hydraulic property characterization and horizontal access to irrigated areas through the trench face. This trench is referred to as the Jornada trench. During excavation, soil core samples were taken at $0.5-m$ horizontal intervals along the length of the trench. The cores were taken at nine depths, down to $5.8 \mathrm{~m}$, for laboratory determination of bulk density, particle-size distribution, saturated hydraulic conductivity, and water retention characteristics.

Nine soil horizons were identified, based on the observed morphological horizons on the west wall of the trench (Wierenga et al. 1989). Textural classifications of the nine soil horizons, based on particle-size analyses (Gee and Bauder 1986), range from sand to sandy loam (Wierenga et al. 1989). The predominant soil type is sandy loam. The average bulk densities of the soil horizons range from 1.66 to $1.74 \mathrm{~g} / \mathrm{cm}^{3}$.

A plan view of the trench and irrigated experimental plots, designated Plots 1 and 2, is shown in Figure 2.1. The three rows of neutron probe access tubes in the vicinity of Plot 2 are located approximately 2, 6, and $10 \mathrm{~m}$ from the trench face. These rows will be referred to as transects 1, 2, and 3, respectively.

For this study, we only considered the first experiment conducted on Plot 2 (experiment 2A), located on the north side of the trench. The first experiment conducted on Plot 1 was not simulated because of an undetermined amount of excess runoff water that entered the west side of the plot after a thunderstorm. These experiments are part of ongoing studies, and are therefore referred to here as the first experiments on each of the respective plots. 


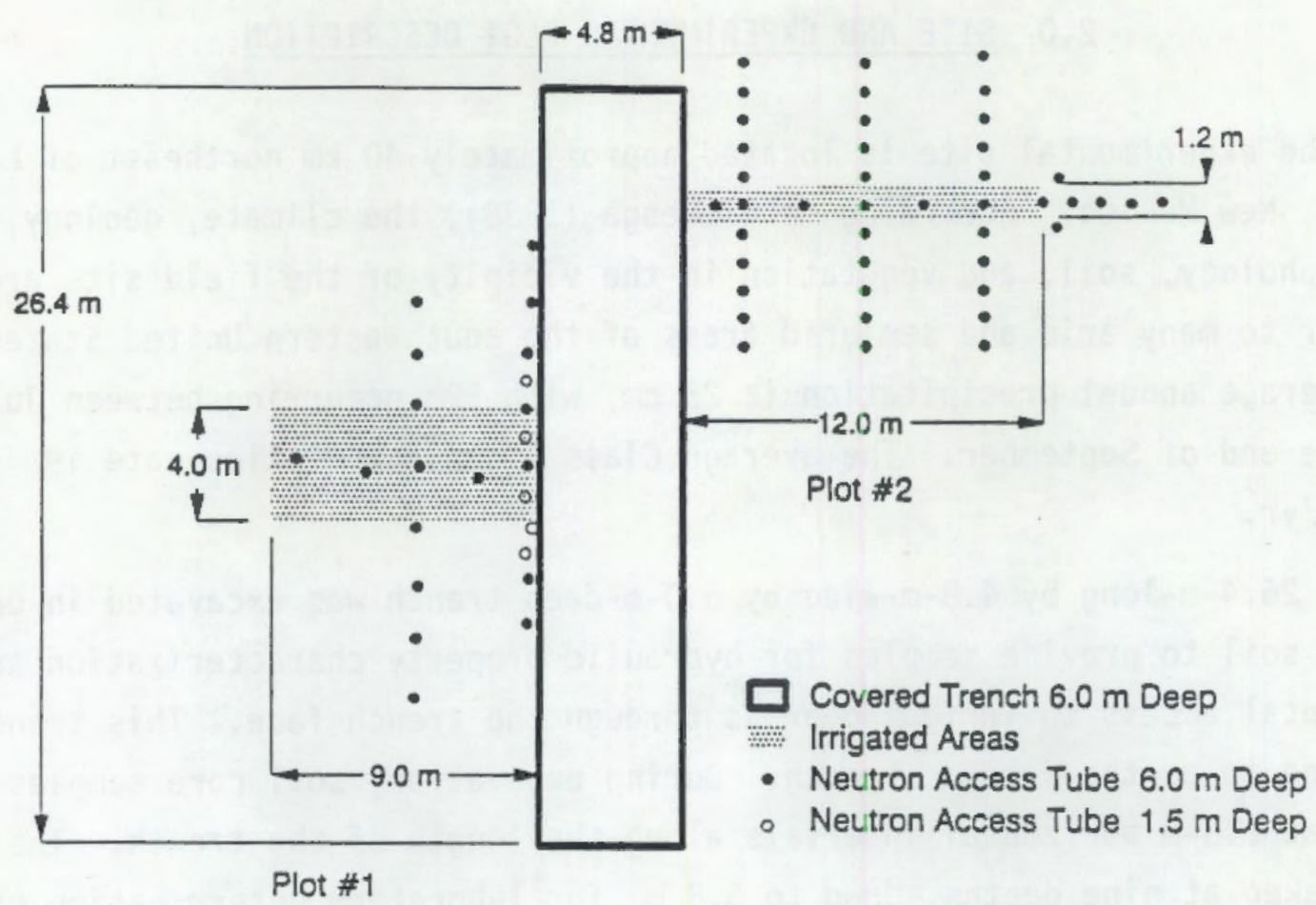

FIGURE 2.1. Plan View of the Jornada Trench Experimental Site (from Wierenga et al. 1989)

Experiment $2 \mathrm{~A}$ consisted of a pulse application of water and solute (tritium and bromide), applied by trickle irrigation over the 1.2- by $12-m$ plot area. Water containing tritium and bromide was applied at a constant and uniformly distributed rate of $0.0043 \mathrm{~m} / \mathrm{d}$ during the first 11.5 days of the experiment. Tritium was applied at a concentration of $0.1 \mu \mathrm{Ci} / \mathrm{mL}$. Irrigation was continued, without solute, for an additional 64 days. Both the trench and the experimental plot were covered to eliminate evaporation and infiltration of natural precipitation during the experiment.

The long, narrow irrigation strip (see Figure 2.1) was used in an attempt to establish a two-dimensional ( $x$ - and $z$-directions) flow regime, with negligible flow in the third dimension (i.e., perpendicular to the trench face). Therefore, experiment $2 \mathrm{~A}$ was simulated with a two-dimensional model domain.

Water and solute movements were monitored in the subsoil during infiltration and redistribution by the use of a neutron probe and solution samplers. Neutron probe measurements were taken at $0.25-m$ intervals down to the $6.0-m$ 
depth. The locations of solution samplers and tensiometers in the trench face adjacent to Plot 2 are shown in Figure 2.2. The solution samplers and tensiometers extend $0.5 \mathrm{~m}$ into the soil profile from the face of the trench. Neutron probe and solute concentration data were used to evaluate the computer simulations.

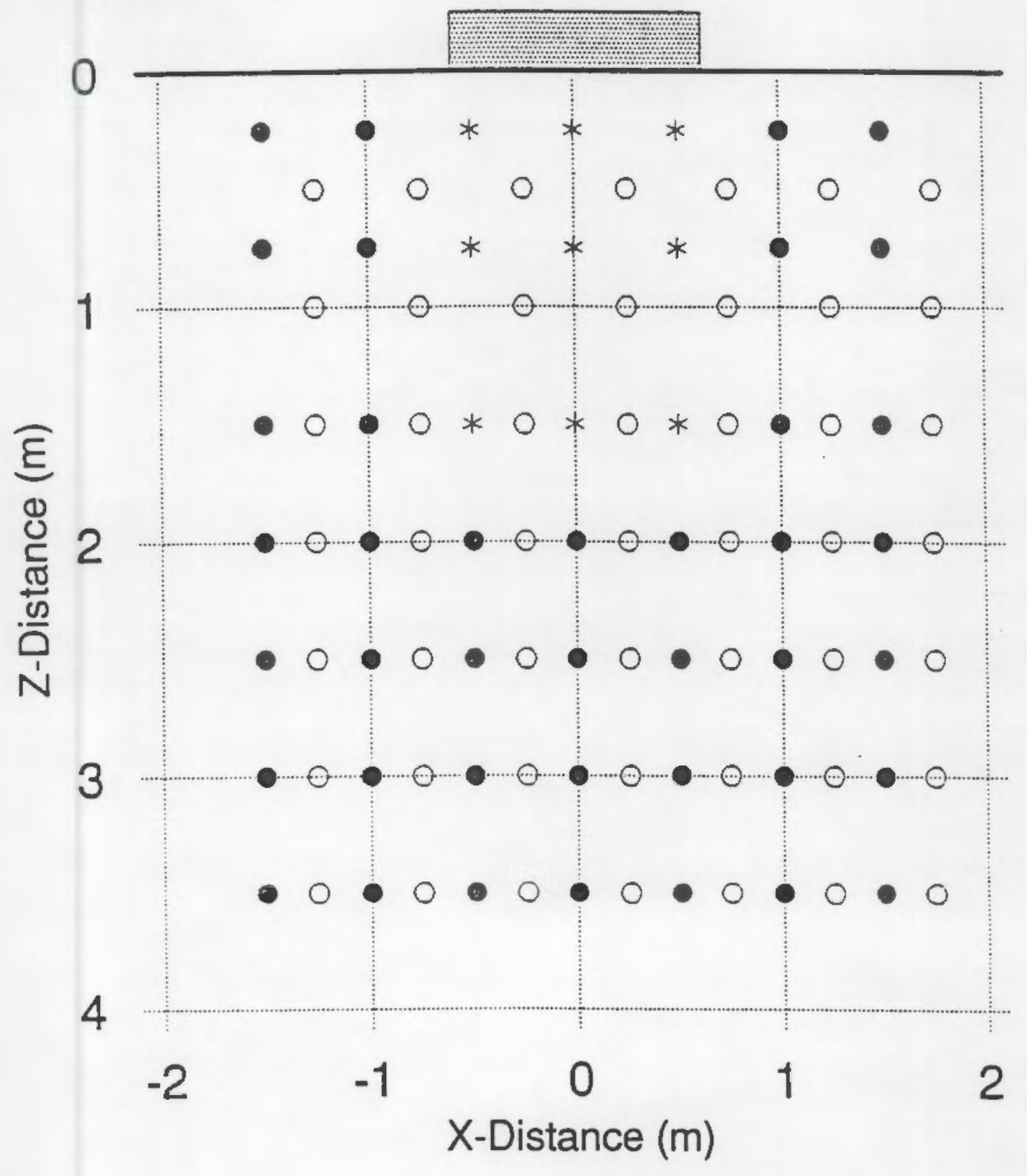

- Tensiometer o Solution Sampler * Sampler/Tensiometer

FIGURE 2.2. Location of Solution Samplers and Tensiometers for Plot 2 
i. 


\subsection{GOVERNING EQUATIONS}

The PORFLO-3 computer code uses generalized, second-order, parabolic transport equations to solve for the dependent variables of hydraulic head, temperature, and concentration. The governing equations are transformed into their algebraic analogs by using the nodal point integration or integrated finite-difference method (Patankar 1980). For the simulations reported here, the algebraic equations were solved using an alternating-direction-implicit (ADI) scheme with standard Picard or modified Picard (Celia et al. 1990) nonlinear iteration. A backward-difference approximation of the time derivative is used.

If sources and sinks are ignored, the two-dimensional pressure-head-based equation describing water flow in unsaturated porous media (also referred to as Richards equation) can be written as

$$
\frac{d \theta}{d h} \frac{\partial h}{\partial t}=\frac{\partial}{\partial x}\left[k_{x} k_{r} \frac{\partial h}{\partial x}\right]+\frac{\partial}{\partial z}\left[k_{z} k_{r}\left(\frac{\partial h}{\partial z}+1\right)\right]
$$

where $\frac{d \theta}{d h}=$ specific moisture capacity

$$
K=\text { saturated hydraulic conductivity tensor }
$$$$
k_{r}=\text { relative permeability }
$$

$h=$ pressure head (negative for unsaturated conditions)

$\theta=$ volumetric water content

$x=$ horizontal coordinate

$z=$ vertical coordinate

$\mathrm{t}=\mathrm{time}$.

In this study, the pressure-saturation-permeability relationships were defined by (van Genuchten 1980)

$$
\theta=\left(\begin{array}{ll}
\theta_{S} & h \geq 0 \\
\theta_{r}+\left(\theta_{S}-\theta_{r}\right)\left[1+(-a h)^{n}\right]-m
\end{array}\right)^{h<0}
$$




$$
k_{r}=S_{e^{1 / 2}}\left[1-\left(1-S_{\left.e^{1 / m}\right) m}^{m}\right]^{2}\right.
$$

where $\theta_{S}=$ saturated water content

$$
\begin{aligned}
\theta_{r} & =\text { residual water content } \\
a_{,} n & =\text { curve-fitting parameters } \\
m & =1-1 / n \\
s_{e} & =\left(\theta-\theta_{r}\right) /\left(\theta_{s}-\theta_{r}\right) .
\end{aligned}
$$

A generalized form of the convection-dispersion equation was used to simulate transport. Neglecting radioactive decay, the convection-dispersion equation for a two-dimensional system can be expressed as

$$
\frac{\partial}{\partial t}(R \theta C)=\frac{\partial}{\partial x}\left(\theta D \frac{\partial C}{\partial x}-q_{x} C\right)+\frac{\partial}{\partial z}\left(\theta D \frac{\partial C}{\partial z}-q_{z} C\right)
$$

where $R=$ retardation factor

$D=$ dispersion coefficient

$q=$ Darcian flux

$C=$ species concentration in the liquid phase.

A normalized or relative concentration was used with the normalization constant equal to the average concentration applied during the first 11.5 days of the experiment. The 12.26-year radioactive half-life for tritium was not considered during the 277-day simulation period.

The $x$ - and $z$-components of the Darcian fluxes are defined by

$$
\begin{aligned}
& q x=K_{x} \frac{\partial h}{\partial x} \\
& q z=K_{z}+K_{z} \frac{\partial h}{\partial z}
\end{aligned}
$$

The dispersion coefficient, $D$, can be defined as 


$$
\theta D=\theta D_{m}+\epsilon|q|
$$

where $D_{m}$ is the molecular diffusion coefficient, $\epsilon$ is dispersivity, and $|q|$ is the magnitude of the Darcian flux. Dispersivities were assumed to be homogeneous and isotropic. 


\subsection{NUMERICAL SIMULATIONS}

The Jornada trench experiments provide detailed data on spatially heterogeneous soil hydraulic properties and initial moisture conditions. Several modeling scenarios were evaluated to investigate the influence of natural heterogeneity on the observed data.

\subsection{MODELING SCENARIOS}

Three cases were simulated. Case 1 represents the use of average site data with no attempt at model calibration. A uniform soil profile was assumed with homogeneous and isotropic hydraulic and transport properties. A uniform model was used, rather than a nine-layer model that would better represent the observed soil morphology, because simulations reported by Wierenga et al. (1990) show no clear advantage in using a layered model over a uniform model for predicting infiltration for the Plot 1 experiment.

For Case 1, soil hydraulic properties were determined as the arithmetic means of the parameters derived from laboratory measurements of water retention and the geometric mean of laboratory-measured saturated hydraulic conductivities. These parameters and measurements were taken from the Las Cruces trench site database (Wierenga et al. 1989). Estimates of the transport parameters were obtained from Wierenga et al. (1990).

For Case 2, a random field generator was used to sample the cumulative probability distribution of the laboratory-measured saturated hydraulic conductivities and to assign saturated hydraulic conductivities to elements in the model domain. The remaining aspects of Case 2 were the same as those used for case 1 .

For Case 3, different water retention curve parameters were used that were derived by refitting the water retention data after constraining the residual water content, $\theta_{r}$, to a value less than the minimum observed initial water content. This enabled the observed initial water contents to be more accurately represented in the numerical model, relative to using the parameters reported by Wierenga et al. (1990). 
A random field generator was again used to generate a randomly heterogeneous hydraulic conductivity field for Case 3. In addition, saturated hydraulic conductivities were assumed to be anisotropic, with $\mathrm{K}_{\mathbf{x}}=1.5 \mathrm{~K}_{\mathbf{z}}$. This anisotropy ratio was chosen in an attempt to reproduce the observed horizontal spread of the water plume.

The Case 3 simulation was run with a modifed version of PORFLO-3, in which a mixed form of the flow equation with a modified Picard iteration method (Celia et al. 1990) was incorporated. This formulation has been shown to be perfectly mass conservative without requiring any additional computational effort, relative to the head-based form of the flow equation with standard Picard iteration that is currently employed in PORFLO-3. The differences between the two solution methods are summarized in the appendix.

Soil heterogeneity was explicitly incorporated into the model domains for Cases 2 and 3. More sophisticated methods have been developed for incorporating and accounting for the effects of soil heterogeneity (Mantoglou and Gelhar 1987; Tompson et al. 1987). However, Cases 2 and 3 simply represent our initial attempts to reproduce some of the heterogeneity shown in the field results.

\subsection{INITIAL AND BOUNDARY CONDITIONS}

The initial conditions used for the Case 1 and 2 simulations were derived from the observed tensions reported in the Las Cruces trench site database (hereinafter referred to as the database). The initial tensions assigned to depths less than $1 \mathrm{~m}$ were determined from depth-averaged tensiometer measurements on day 1 of the experiment. Tensions at these depths were within the range of tensiometer measurements as a result of recent precipitation prior to the start of the experiment.

The initial tensions for depths greater than $1 \mathrm{~m}$ were too high to be in the range of tensiometer measurement $(0$ to $\approx 7 \mathrm{~m})$. Tensions below the $1-\mathrm{m}$ depth were determined from thermocouple psychrometer measurements on soil samples collected during installation of neutron probe access tubes in the plot, some time prior to the start of the experiment. These calculated tensions ranged from approximately 119 to $>600 \mathrm{~m}$. Attempts to use these tensions as initial conditions resulted in poor mass balance and too much lateral spreading 
of the water plume using the standard Picard version of the code. Therefore, the initial tensions that were used for the Case 1 and 2 simulations, below the $1-m$ depth, were linearly interpolated between the depth-averaged initial tension at the 1-m depth and an assumed maximum tension of $100 \mathrm{~m}$ at the $5-\mathrm{m}$ depth. The poor mass balance obtained using drier initial conditions motivated the development of the modified Picard version of the code.

Initial water contents, measured below the $1-m$ depth, were 2 to 4 vol\% lower than the average value of the fitted residual water content $18.3 \%$; Wierenga et al. 1990) for much of the lower part of the soil profile. Initial tensions cannot be calculated from these field-measured water contents, using the water retention curve parameters reported in the database, because the fitted residual water content is greater than field-measured water contents.

To represent the initial observed water contents more accurately for the Case 3 simulation, different water retention curve parameters were used that were derived by refitting the water retention data after constraining $\theta_{r}$ to a value less than the minimum observed initial water content. Initial tensions were then calculated using these revised parameters and the depthaveraged initial water contents measured from neutron probe transect 2 . The initial water content profiles, corresponding to the initial conditions used for model simulations are depicted in Figure 4.1. The initial, normalized solute concentration was specifed as zero for all simulations.

Experiment $2 \mathrm{~A}$ was specifically designed to establish a two-dimensional flow regime. Cases 1 and 2 simulated a two-dimensional, 10-m-wide by 5-m-deep cross section. Case 3 simulated a two-dimensional, 12-m-wide by 6 -m-deep cross section. These dimensions were sufficient to maintain the water contents at or near the initial conditions with the hydraulic properties and initial conditions that were used. Uniform 10-cm node spacing was used in both the horizontal and vertical directions for all simulations.

A $0.0043-m / d$ flux was prescribed as the surface boundary condition that corresponded to the irrigated strip source for the the first 75.5 days in the simulations. After 75.5 days, this boundary was changed to a zero-flux boundary. A normalized source concentration of 1.0 was specified for the strip source boundary during the first 11.5 days in the simulations. After 11.5 days, this boundary was changed to a zero-concentration boundary. 


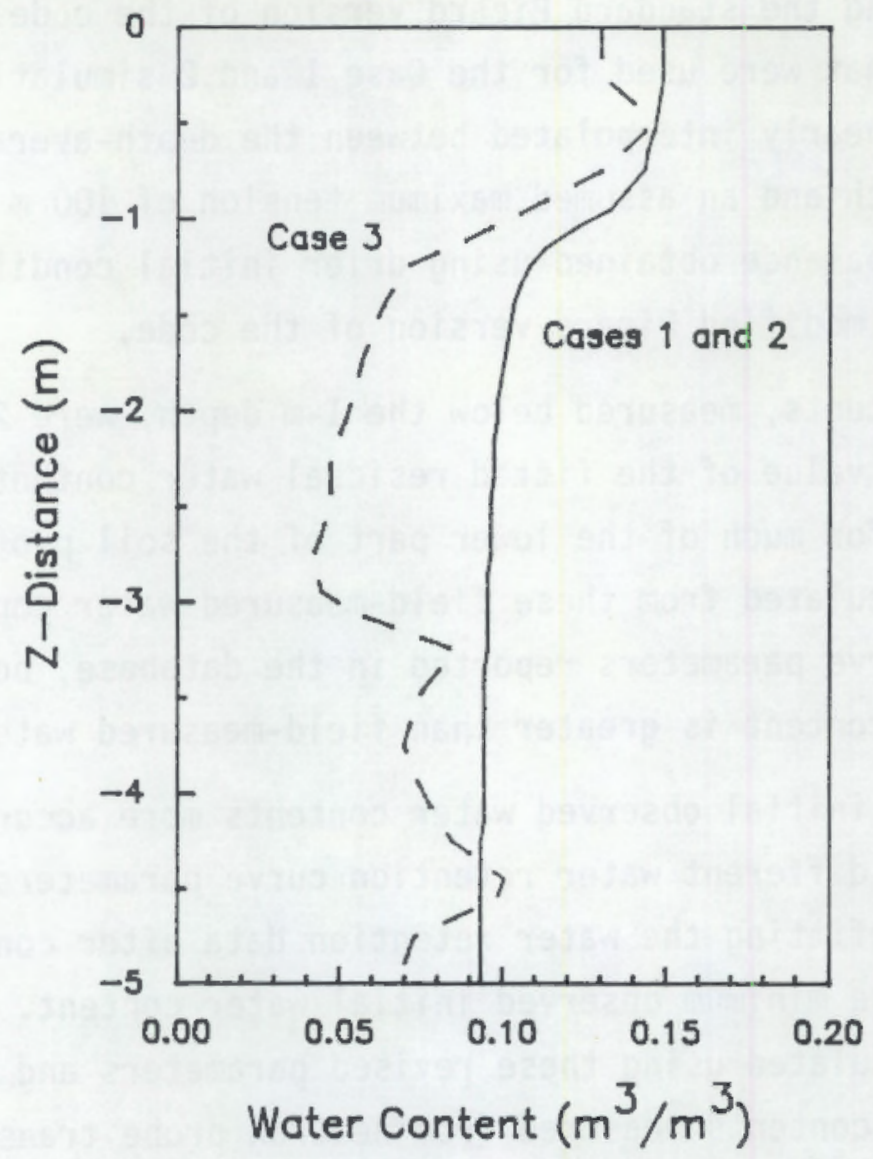

FIGURE 4.1. Initial Water Content Profiles Used for Model Simulations Zero-flux and zero-concentration conditions were imposed on the remainder of the upper boundary and on the side and bottom boundaries. A variable time step was used, with a starting value of $\Delta t=0.05$ day and a maximum of $\Delta t=2$ days. Between 325 and 364 time steps were required for the 277-day simulations, with an average of $54 \mathrm{~min}$ on a Cray X-MP/18 computer, for the Case 1 and 2 simulations.

\subsection{FLOW AND TRANSPORT PARAMETERS}

The database contains soil property characterization data; water and solute application rate information; and measurements of volumetric water content, tensions, and relative tritium and bromide concentrations for the trench experiments. The soil property data include laboratory and in situ saturated hydraulic conductivities, particle-size distribution data, measured 
water retention data, and estimates of the van Genuchten (1980) water retention curve parameters.

Estimates of the van Genuchten (1980) water retention curve parameters and average, laboratory-measured $K_{s}$ values are shown in Table 4.1. The coefficients of variability ( $\mathrm{CV}=\mathrm{mean} / \mathrm{standard}$ deviation) of the $\log \mathrm{K}_{\mathrm{s}}$ values and the average $K_{S}$ values for each layer suggest that a single layer, heterogeneous model may represent the site as well as a layered model.

The parameter estimates reported for each core sample in the database were reviewed. As a result of this review, the data set was modified by omitting several incomplete sets of water retention parameters and two samples that were duplicated and had parameters that appeared to be outliers (samples 6-26 and B-25). New averages were calculated from the remaining samples. The new averages were then used for the Case 1 and 2 simulations.

Simulation results that were obtained using the parameter estimates shown in Table 4.1 are reported by Wierenga et al. (1990). From inspection of the measured initial water contents, it is apparent that the initial water contents below the 1-m depth cannot be accurately represented in a numerical model using the fitted parameters from the database because $\theta_{r}$ is greater than the initial water contents in much of the lower part of the profile.

To represent more accurately the initial water contents, initial tensions were calculated from revised parameter estimates obtained from Dr. J. B. Kool, HydroGeoLogic, Herndon, Virginia, using the depth-averaged initial water

TABLE 4.1. Hydraulic Parameter Estimates for the Las Cruces Trench Site (after Wierenga et al. 1990)

\begin{tabular}{|c|c|c|c|c|c|c|c|}
\hline & Depth (m) & $\begin{array}{c}{ }^{\theta} \mathrm{m}_{\mathrm{s}} \\
\left.\mathrm{m}^{3}\right)\end{array}$ & $\begin{array}{c}\theta \\
\left(m^{3} / m^{3}\right) \\
\end{array}$ & $\stackrel{a}{(1 / m)}$ & n & $\begin{array}{l}K_{5} \\
(m / d) \\
\end{array}$ & $\begin{array}{c}\text { CV }(\%) \\
(\log 10 \mathrm{Ks})\end{array}$ \\
\hline 1 & 0 to 0.15 & 0.3483 & 0.0949 & 4.194 & 1.9036 & 5.392 & 6.8 \\
\hline & 0.15 to 1.40 & 0.3434 & 0.0914 & 6.237 & 1.5278 & 2.500 & 17.1 \\
\hline 3 & 1.40 to 2.05 & 0.3359 & 0.0849 & 5.960 & 1.5742 & 2.669 & 18.6 \\
\hline & 2.05 to 2.50 & 0.3129 & 0.0714 & 6.772 & 1.5373 & 2.998 & 24.9 \\
\hline 5 & 2.50 to 3.05 & 0.3021 & 0.0716 & 4.039 & 1.5496 & 2.500 & 23.0 \\
\hline & 3.05 to 3.70 & 0.2942 & 0.0896 & 7.029 & 1.7117 & 3.340 & 28.5 \\
\hline & 3.70 to 4.60 & 0.3104 & 0.0726 & 2.719 & 1.4177 & 2.206 & 27.9 \\
\hline & 4.60 to 5.40 & 0.3248 & 0.0834 & 4.110 & 1.3826 & 1.715 & 30.2 \\
\hline & 5.40 to 6.00 & 0.3061 & 0.0778 & 4.679 & 1.4315 & 2.259 & 23.7 \\
\hline Ail & 0 to 6.00 & 0.3209 & 0.0828 & 5.501 & 1.5093 & 2.701 & 23.6 \\
\hline
\end{tabular}


contents from transect 2 . The revised parameters were derived by refitting the water retention data after constraining $\theta_{r}$ to a value less than the minimum observed initial water content. The revised parameters that were used for the Case 3 simulation, as well as the parameters used for the Case 1 and 2 simulations, are listed in Table 4.2. The curves representing the parameters in Table 4.2 are shown in Figure 4.2.

The cumulative probability distribution of the laboratory-measured saturated hydraulic conductivities was generated from an empirical distribution function (Mood et al. 1974). The laboratory-measured saturated hydraulic conductivities are not normally or log-nomally distributed. The cumulative probability distribution, representing the cumulative distribution function (CDF) for the laboratory-measured saturated hydraulic conductivities, is depicted in Figure 4.3. A random field generator was used to sample the CDF and to assign saturated hydraulic conductivity values to elements in the model domains for Cases 2 and 3.

Analyses of log-transformed, in situ measurements of $K_{s}$ from the trench site indicate that horizontal correlation lengths range from 2.0 to $2.5 \mathrm{~m}$, and vertical correlation lengths range from 0.15 to $0.5 \mathrm{~m}$ (Jacobson 1990; Nicholson et al. 1989). No spatial correlation was considered during the generation of the random hydraulic conductivity fields. Not accounting for spatial correlation amounts to assuming a pure nugget effect, which corresponds to a total lack of structure on the spacing of the model grid (Journel and Huijbregts 1978). This was considered to be a reasonable first approximation.

TABLE 4.2. Hydraulic Parameters Used in Model Simulations

$\frac{\text { Parameters }}{\langle K x\rangle, \quad\langle K z\rangle(m / d)}$

\begin{tabular}{c}
$\frac{1}{1}$ Model \\
\hline $2.536,2.536$ \\
0.322 \\
0.089 \\
5.377 \\
1.653
\end{tabular}

\begin{tabular}{cc}
$\frac{3}{2}$ & \multicolumn{3}{c}{ Scenario } \\
$(\mathrm{a})$ & $\frac{3}{(b)}$ \\
0.322 & 0.320 \\
0.089 & 0.025 \\
5.377 & 11.2 \\
1.653 & 1.253
\end{tabular}

(a) Individually assigned to elements in the model domain.

(b) Individually assigned to elements in the model domain, with $\mathrm{K}_{\mathrm{x}}=1.5 \mathrm{~K}_{\mathrm{z}}$. 


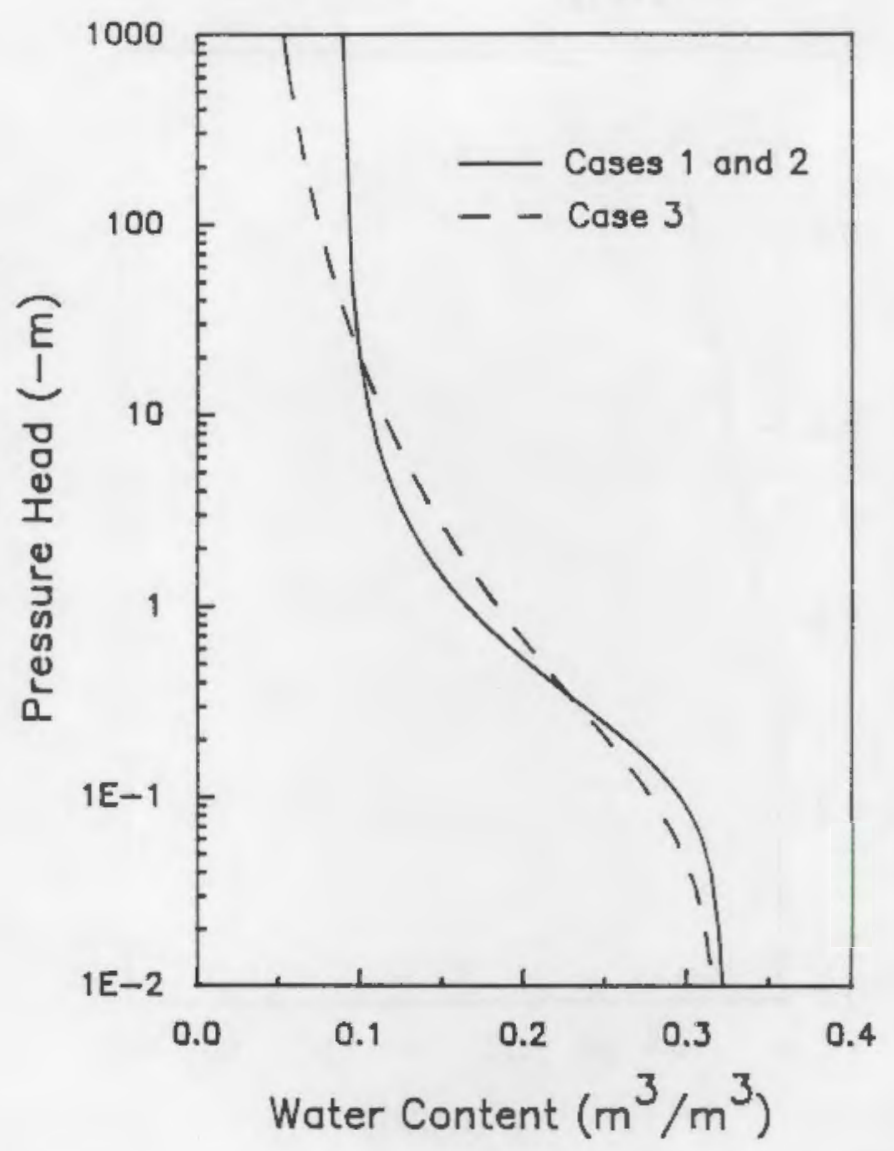

FIGURE 4.2. Water Retention Curves Used for Model Simulations

The transport parameters used for this study were estimated by Wierenga et al. (1990). Estimates of the field transport parameters using the convection-dispersion equation are also reported by Elabd et a1. (1988). For simulation of the transport of tritium, dispersivities were assumed to be homogeneous and isotropic, and the solute was assumed to be nonreactive and nondecaying. Neglecting the radioactive decay of tritium introduces an error of approximately $4 \%$ on day 277 . This error was considered to be negligible in comparison to the experimental errors associated with measurements of solute concentrations and water content.

A retardation factor, $R$, of 1.0 was assumed, with a molecular diffusion coefficient, $D_{m}$, of $1.0 \mathrm{E}-4 \mathrm{~m} / \mathrm{d}$, and dispersivities, $\epsilon$, of $0.05 \mathrm{~m}$. Longitudinal and transverse dispersivities were assumed to be equal. Dispersivity has not been determined for the trench experiment, but field dispersivity values of $0.1 \mathrm{~m}$ or more have been reported (Nielsen et al. 1986). The low 


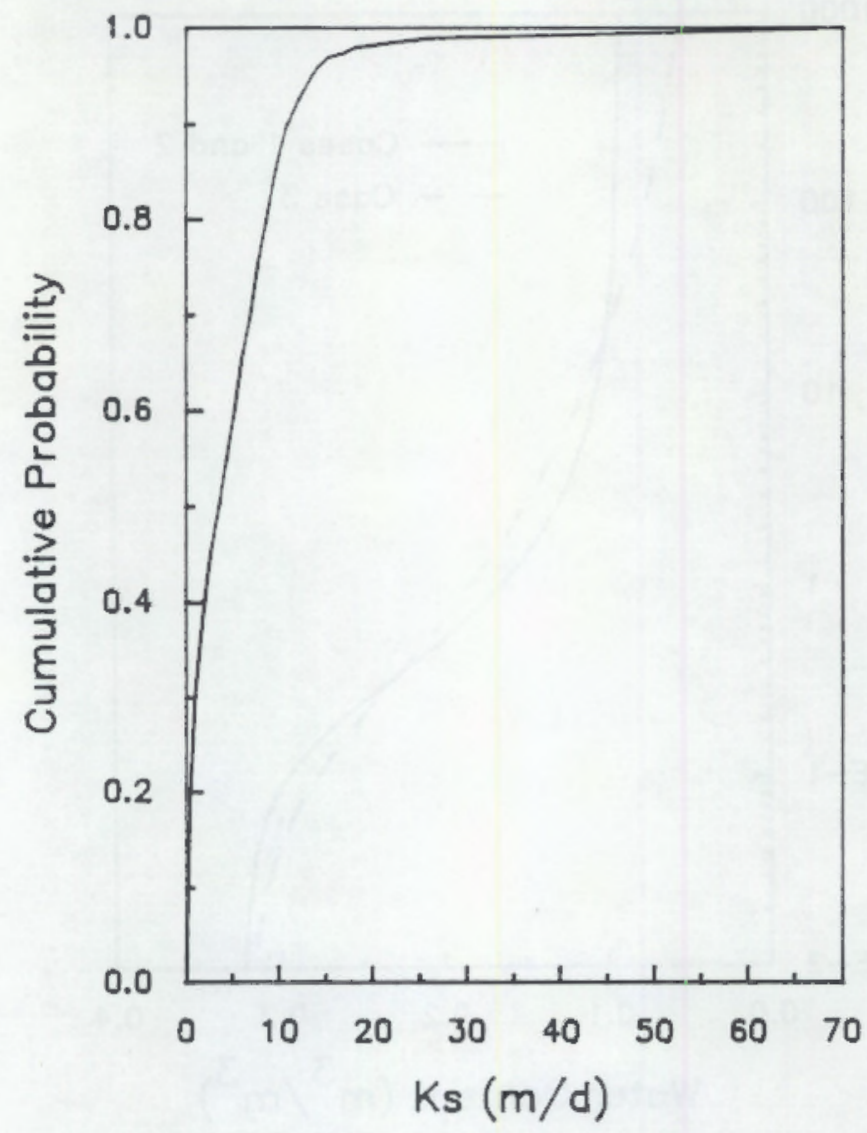

FIGURE 4.3. Cumulative Probability Distribution of Saturated Hydraulic Conductivities

dispersivity values used for this modeling study result in convection- rather than dispersion-dominated transport.

\subsection{SPATIAL MOMENT ANALYSIS}

Spatial moments provide an integral measure of multidimensional mass transport processes. The original intent of the spatial moment analys is in this study was to calculate dispersivities from the observed tritium plume dynamics. Because of differences in the temporal and spatial locations of solute and water content measurements, dispersivities were not estimated from these data. However, the spatial moment analysis was used to provide a quantitative basis for comparing the mean simulated and observed flow behavior. 
The $i j$-th moment, $M$, of the water content or concentration distribution in space is defined as

$$
M_{i j}^{A}(t)=\int_{-\infty}^{\infty} \int_{-\infty}^{\infty} A(x, y, t) x^{i} z^{j} d x d z
$$

where $A(x, y, t)$ represents either the water content change, $\theta$, or the normalized concentration, $C_{n}$, times the volumetric water content, $\theta$.

To account for the fact that different initial water content distributions were used, all flow simulations were evaluated on the basis of water content changes. These water content changes were defined by

$$
\theta(x, z, t)=\theta(x, z, t)-\theta(x, z, t=0)
$$

where the water content representing $t=0$ was taken as the water content measured on day -1 , two days prior to the start of infiltration. All subsequent analyses and comparisons are based on water content changes rather than actual water content.

Tritium concentrations reported in the database are expressed in terms of relative concentrations, $C_{n}$, which are calculated as (Wierenga et al. 1990)

$$
c_{n}=\left(c-C_{b}\right) /\left(C_{0}-C_{b}\right)
$$

where $C$ is the measured count rate (counts/min), $\mathrm{Cb}_{\mathrm{b}}$ is the background count rate (10 counts/min), and $C_{0}$ is the average count rate of the input solution (28060 counts/min).

The integral of Equation (4.1) is defined over all two-dimensional space. However, the integrand will be nonzero only over regions where the concentrations or water content changes are nonzero. Therefore, the spatial moment, $M_{1}$ is an integrated measure of the concentration field or water content distribution only over the extent of the solute or water plume.

The zero-th moment is equal to the total mass or activity of tracer in solution or the change in total mass of water in the system. The first moment, 
normalized by the total mass, defines the location of the center (subscript c) of solute or water mass (Freyberg 1986).

$$
\begin{aligned}
& x_{c}=M_{10} / M_{00} \\
& z_{c}=M_{01} / M_{00}
\end{aligned}
$$

The second moment about the center of mass defines a spatial covariance tensor.

$$
\sigma=\left[\begin{array}{cc}
\sigma_{\mathrm{Xx}} & \sigma_{\mathrm{Xz}} \\
\sigma_{\mathrm{zx}} & \sigma_{\mathrm{zz}}
\end{array}\right]
$$

where $\sigma_{x x}=M_{20} / M_{00}-x_{c}{ }^{2}$

$$
\begin{aligned}
& \sigma_{z z}=M_{02} / M_{00}-z_{c}{ }^{2} \\
& \sigma_{x z}=\sigma_{z x}=M_{11} / M_{00}-x_{c} z_{c} .
\end{aligned}
$$

The components of this spatial covariance tensor are physically related to the spread of the water or solute plume about its center of mass (Freyberg 1986).

The flux and concentration boundary conditions were the same for all cases. Therefore, only the first and second spatial moments are emphasized in this analysis, and only the spatial moments of the water content distributions are reported.

The neutron probe water content measurement grid was much coarser than the computational grid used for numerical simulations. Therefore, the simulation results were interpolated to a contour grid, with $0.5-\mathrm{m}$ spacing between grid lines in the $x$-direction and $0.25-m$ spacing between grid lines in the z-direction to match the measurement locations, using the SURFER software package. Inverse, distance-squared, weighted averages were used to 
interpolate values from the simulated water content changes for the contour grid. These interpolated values were then used for spatial moment calculations.

This spatial moment estimation method incorporates a smoothing of the simulated water or solute distribution by the weighted averaging that is used to obtain nodal values for the contour grid. Freyberg (1986) suggests that the estimated values of the coordinates of the center of mass and of the components of the covariance tensor are relatively insensitive to the grid spacing and weighting used for interpolation. Alternative spatial moment estimation methods and techniques for reducing possible bias introduced by the grid spacing and weighting used for interpolation are discussed by Barry and Sposito (1990). 
, 


\subsection{RESULTS AND DISCUSSION}

The different modeling scenarios are evaluated by comparing predicted and observed water content changes and solute distributions at times of 11 , 71 , and 276 or 277 days after the start of water application. Neutron probe readings were taken on day 276 , but solute samples were collected on day 277 . Therefore, the simulation results for day 277 are reported. The first and second spatial moments of the water content changes are also calculated to provide a quantitative basis for comparing the mean simulated and observed flow behavior.

\subsection{FIELD OBSERVATIONS}

The initial water content distributions for transects 1, 2, and 3 , measured two days before the start of irrigation (day -1), are shown in Figure 5.1. The initial water content distribution is highly variable, with the upper 1.0 to $1.5 \mathrm{~m}$ of the profile generally being wetter than the deeper depths. Differences in water content between the upper and lower profile are reflected in the depth-dependent pressure heads that were assigned as initial conditions.

The observed water content changes on days 11,71 , and 276, corresponding to measurements from transects 1,2 , and 3 , are shown in Figures 5.2, 5.3, and 5.4, respectively. Comparisons of the water content changes for the three transects indicate considerable temporal and spatial variation with regard to both the depth of penetration and the spread of the moisture plume. These differences suggest that even though the experiment was specifically designed to create a two-dimensional flow regime, three-dimensional flow effects were significant.

The water content changes measured along transects 2 and 3 are closer to each other than to the changes measured along transect 1 . This observation suggests that the water content measurements from transect 1 (located $2 \mathrm{~m}$ from the trench face) and the solution samplers (located $0.5 \mathrm{~m}$ from the trench face) may have been affected by the trench. Considering these edge effects and the apparent three-dimensional flow, it is probably most appropriate to compare simulated water content changes to observations from transect 2 . 

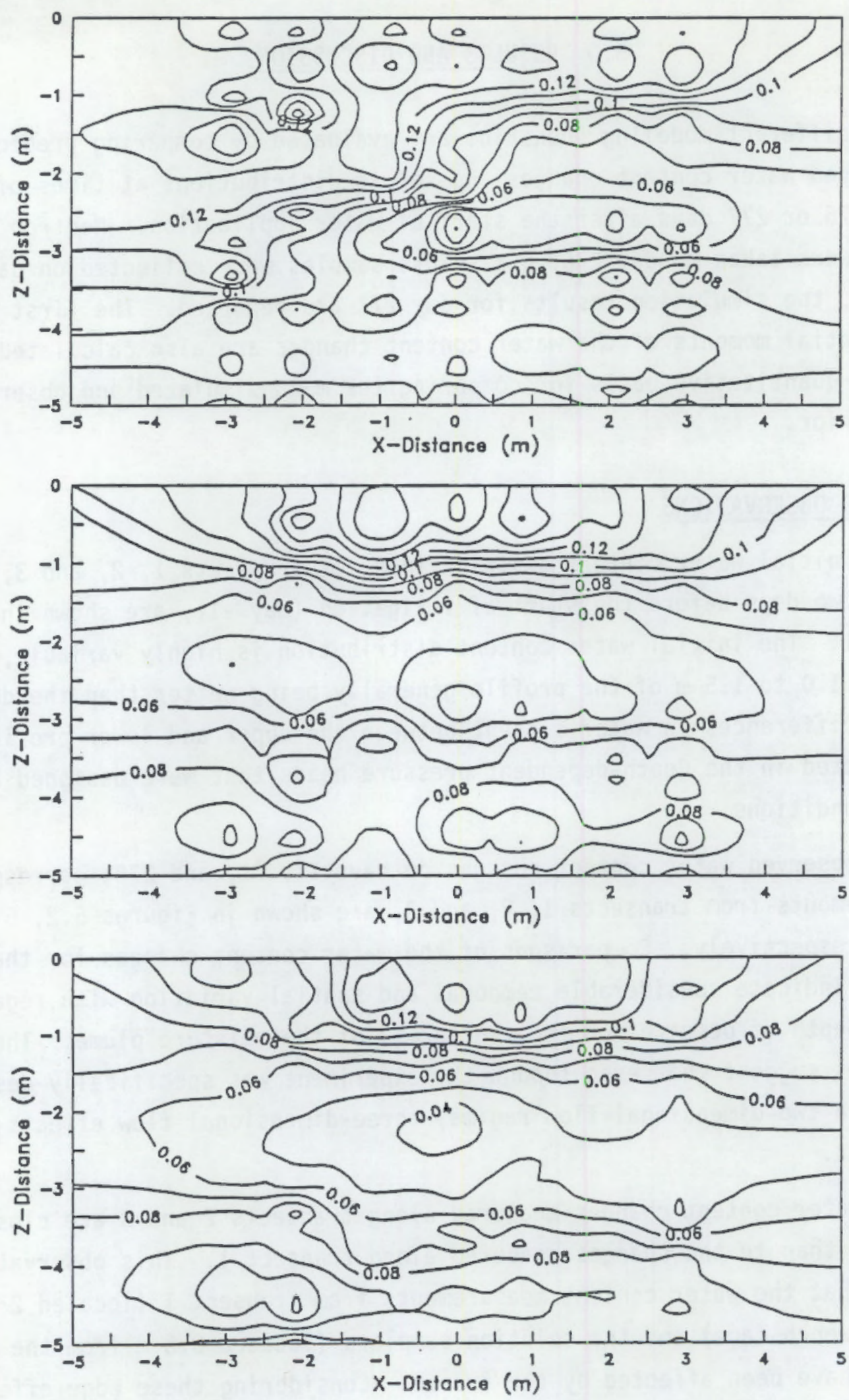

FIGURE 5.1. Observed Initial Water Content for Transects 1,2 , and 3 (top to bottom). Contour interval $=0.01 \mathrm{~m}^{3} / \mathrm{m}^{3}$. 

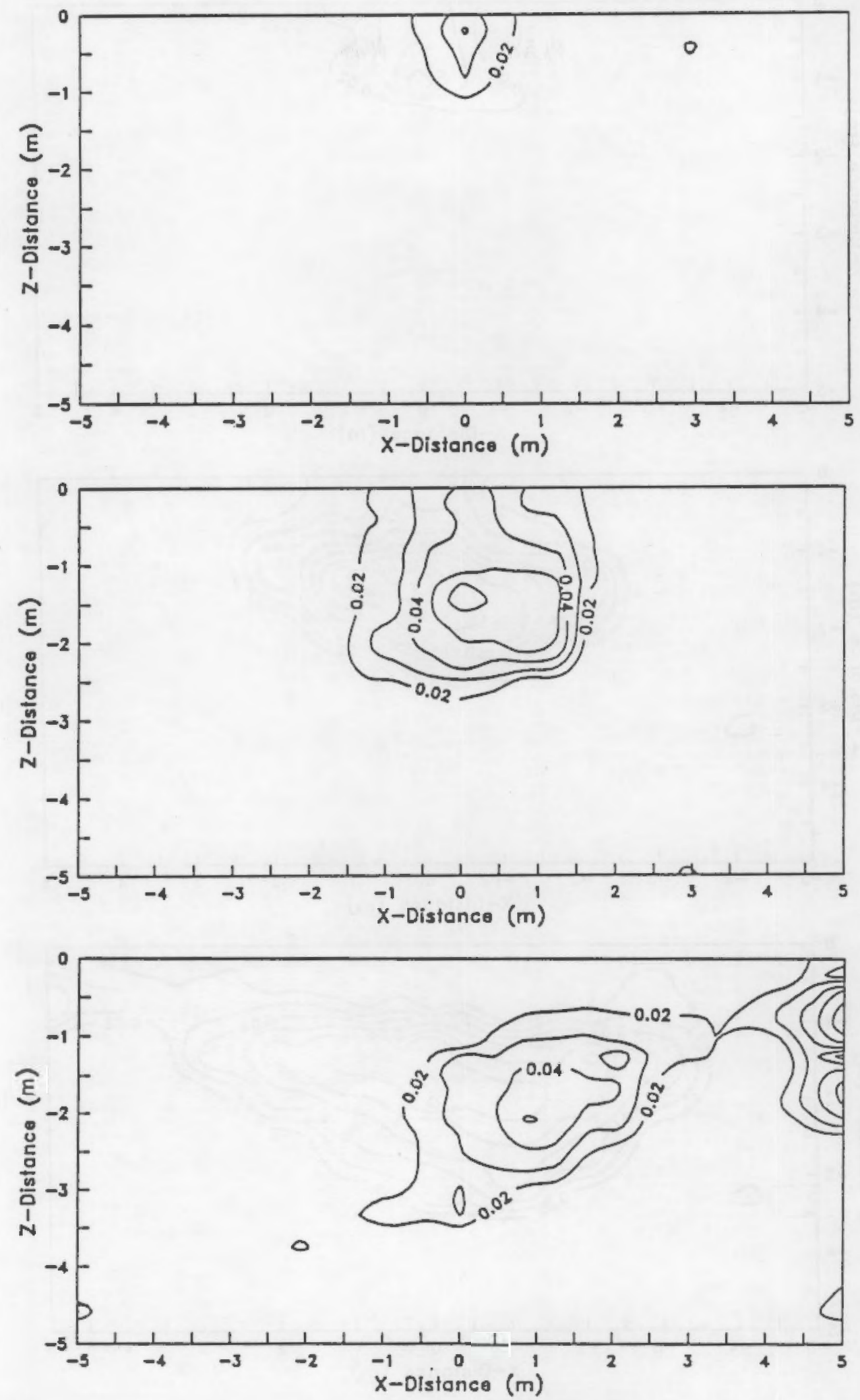

FIGURE 5.2. Observed Water Content Changes for Transect 1 for Days 11, 71, and 276 (top to bottom). Contour interval $=0.01 \mathrm{~m}^{3} / \mathrm{m}^{3}$. 

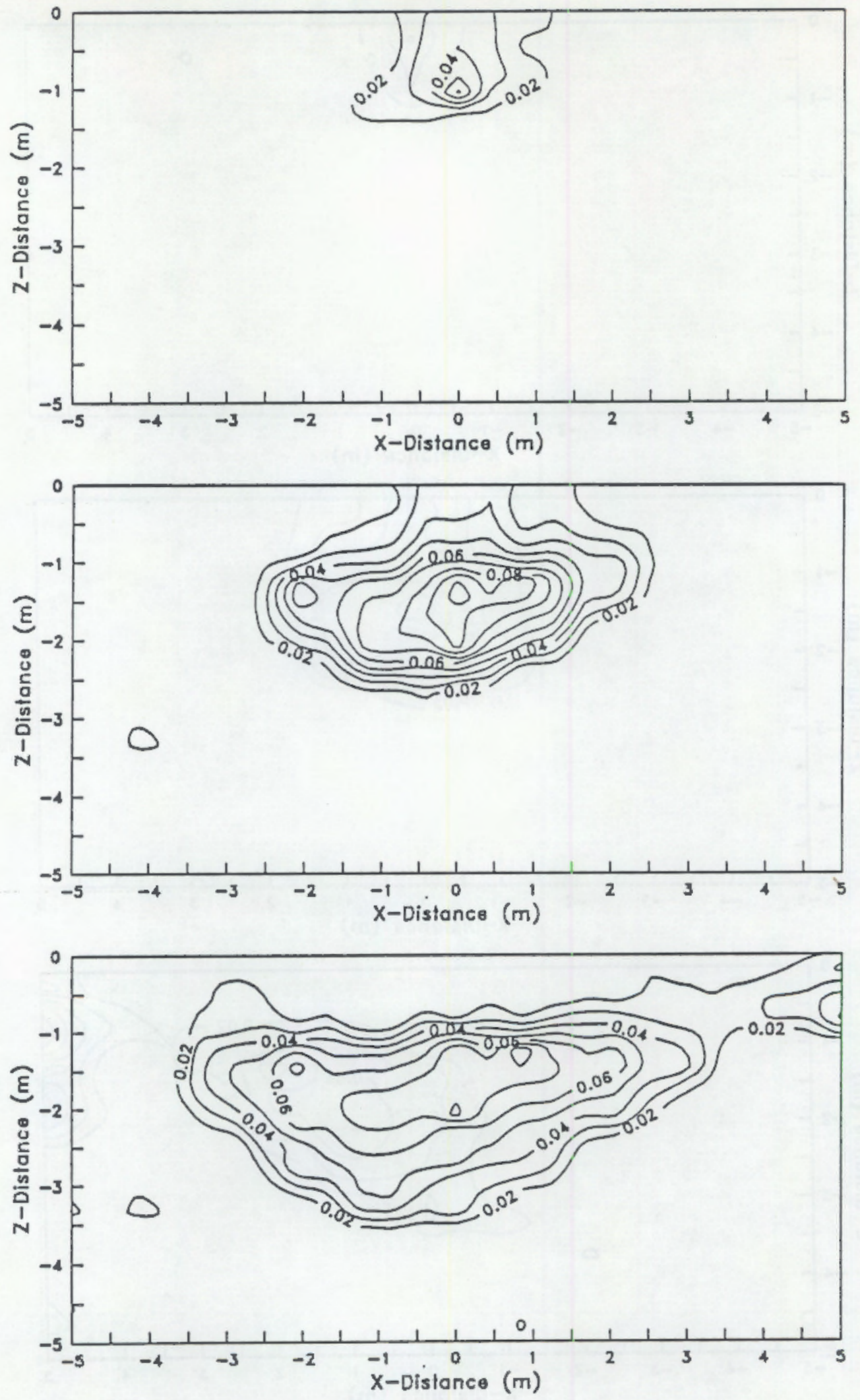

FIGURE 5.3. Observed Water Content Changes for Transect 2 for Days 11, 71 , and 276 (top to bottom). Contour interval $=0.01 \mathrm{~m}^{3} / \mathrm{m}^{3}$. 

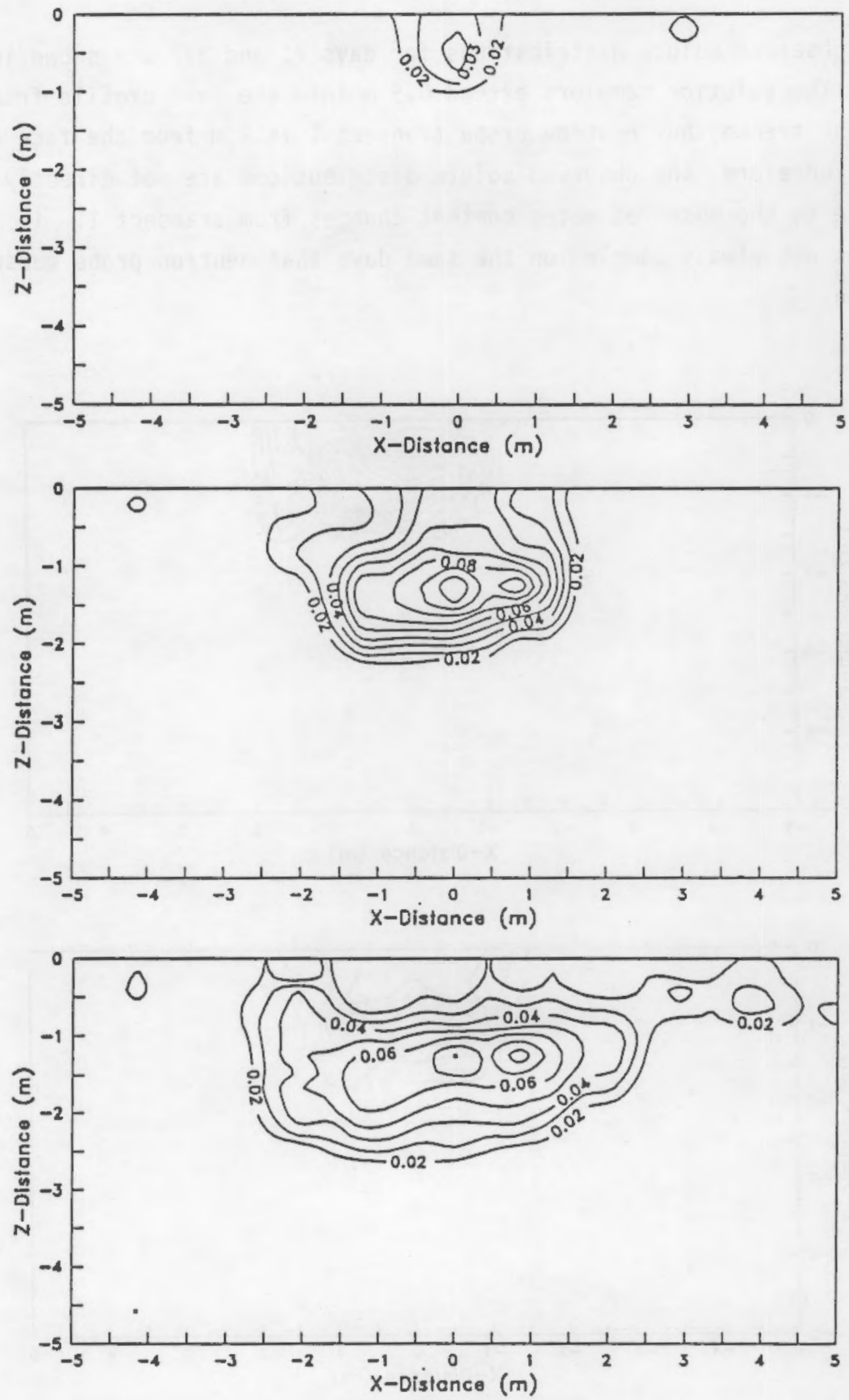

FIGURE 5.4. Observed Water Content Changes for Transect 3 for Days 11, 71, and 276 (top to bottom). Contour interval $=0.01 \mathrm{~m}^{3} / \mathrm{m}^{3}$. 
The observed solute distributions for days 71 and 277 are shown in Figure 5.5. The solution samplers extend $0.5 \mathrm{~m}$ into the soil profile from the face of the trench, but neutron probe transect 1 is $2 \mathrm{~m}$ from the face of the trench. Therefore, the observed solute distributions are not directly comparable to the observed water content changes from transect 1. In addition, solute was not always sampled on the same days that neutron probe measurements were taken.
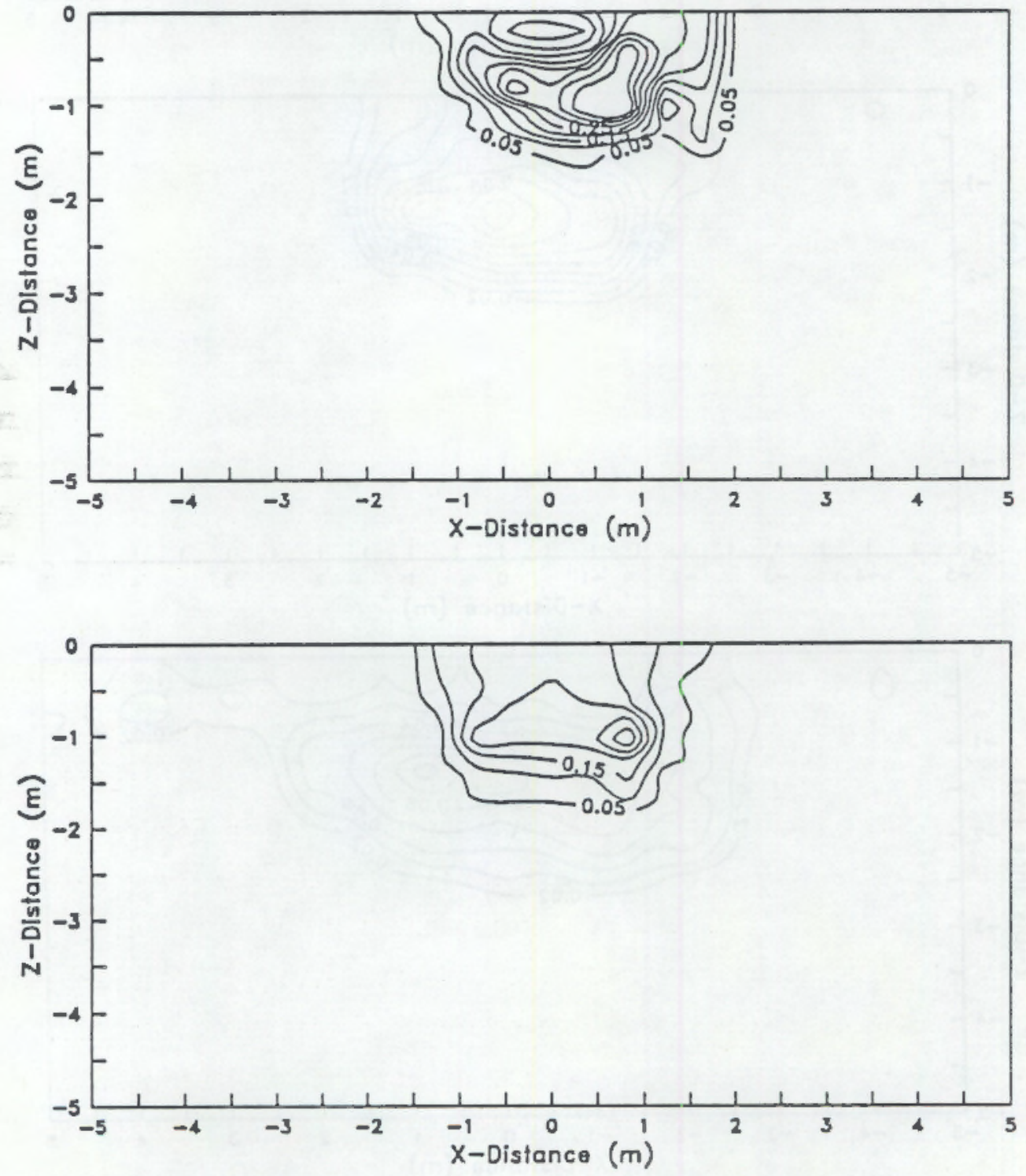

FIGURE 5.5. Observed Relative Tritium Concentrations for Days 71 and 277 (top and bottom). Contour interval $=0.05$. 


\subsection{SIMULATION RESULTS}

The water content changes from the Case 1 simulation for days 11, 71, and 277 are shown in Figure 5.6. This modeling scenario represents the use of average site data with no attempt at model calibration. The water content changes produced by the Case 1 simulation are symmetric about the center line of the irrigated plot area. This case could actually have been modeled with half as many nodes, using the center line of the irrigated area as an axis of symmetry. However, the full two-dimensional domain was used to facilitate later comparisons without having to generate a mirror image of the simulation results.

Comparing the results of Case 1 to the observed water content changes measured from transect 2 (see Figure 5.3) indicates that the depths of penetration and lateral spreading of the moisture plume are similar. The leading edges of the simulated water plume extend approximately $0.35 \mathrm{~m}$ deeper and slightly farther laterally than the observed water plume on day 277 .

The contours generated from the simulation results are much smoother than the irregular contours generated from the observed data, as expected. Differences in the magnitude of the observed and simulated water content changes are primarily a result of not accurately representing the initial water content distribution in the model. However, the depth of infiltration and spread of the simulated water plume match the observed data fairly well.

The relative concentrations of tritium from Case 1 for days 71 and 277 are shown in Figure 5.7. The concentration front lags behind the water front as a result of displacement of the initial water in the soil profile. This effect is also seen in the field observations depicted in Figure 5.5. The relative concentrations from Case 1 are similar to the observed relative concentrations shown in Figure 5.5. Again, the simulation results generate smooth, symmetric contours as opposed to the asymmetric, irregular contours generated from the observed data. The observed relative concentration data also show much higher peak concentrations relative to the simulation results. These higher peak concentrations may be related to three-dimensional flow in the field results, differences between the actual and modeled initial water contents, and/or mass balance errors in the numerical solution. 

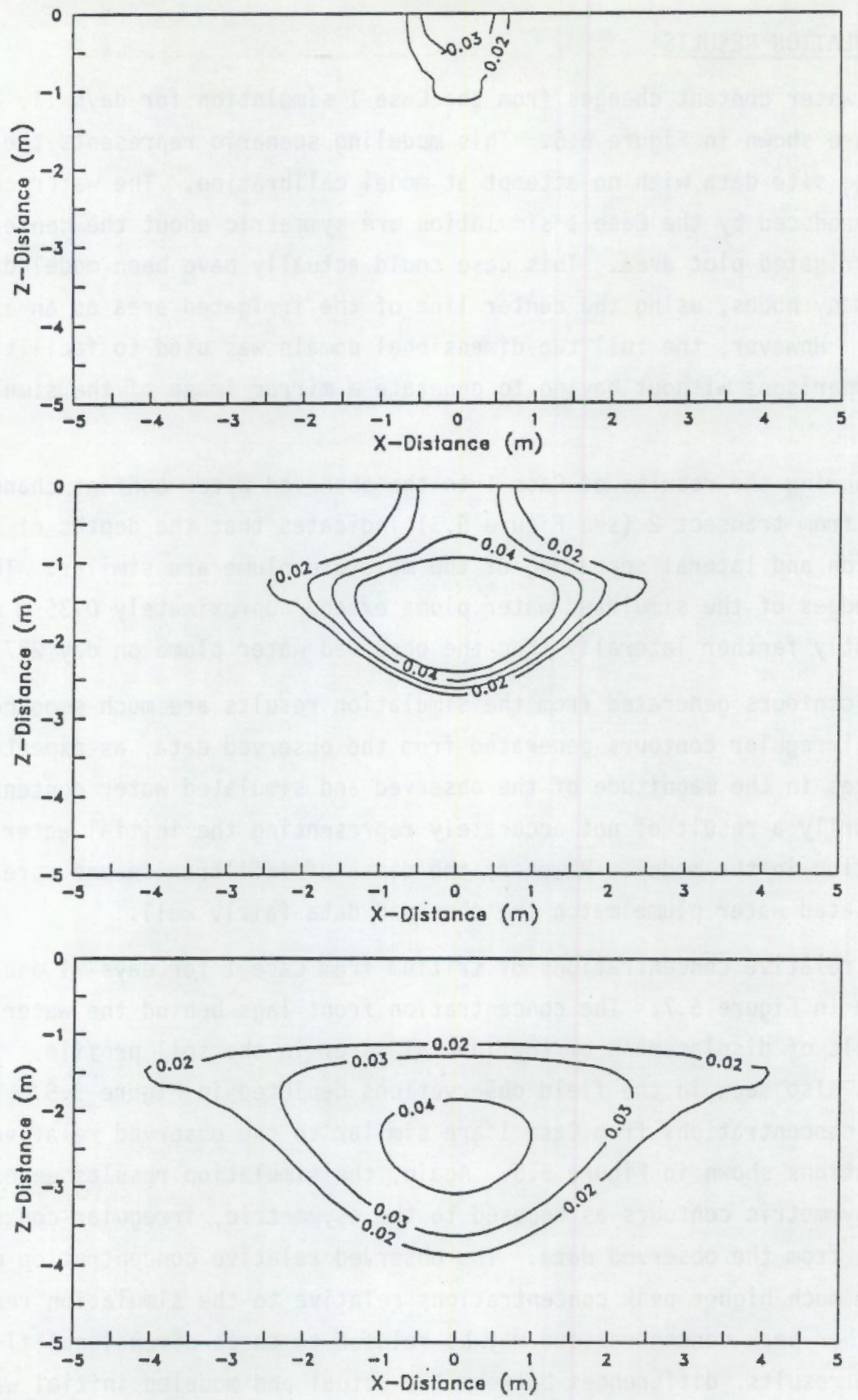

FIGURE 5.6. Simulated Water Content Changes from Case 1 for Days 11, 71, and 277 (top to bottom). Contour interval $=0.01 \mathrm{~m}^{3} / \mathrm{m}^{3}$. 

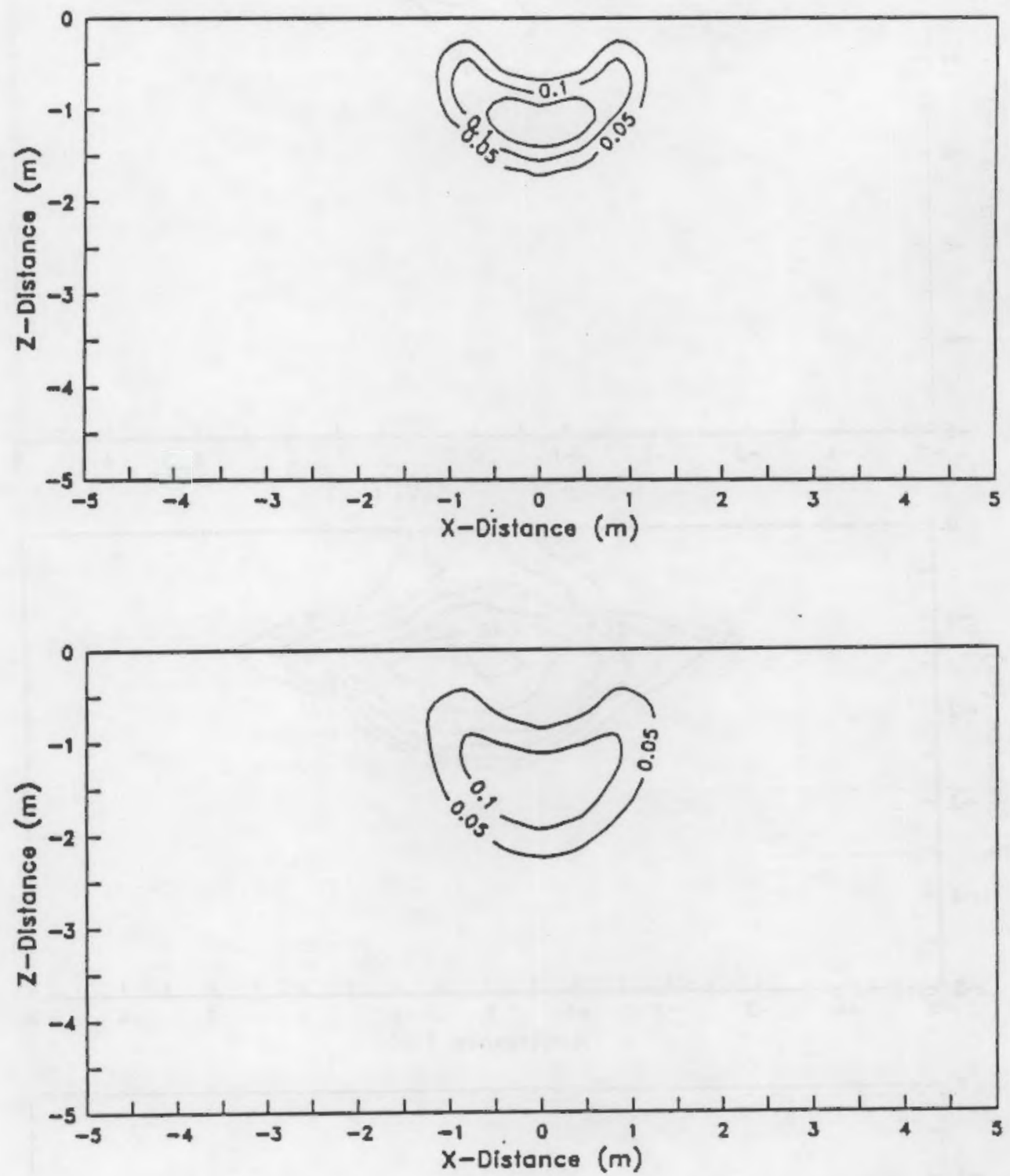

FIGURE 5.7. Simulated Relative Tritium Concentrations from Case 1 for Days 71 and 277 (top and bottom). Contour interval $=0.05$.

The simulated water content changes from Case 2 for days 11, 71, and 277, are shown in Figure 5.8. A randomly heterogeneous hydraulic conductivity field was generated for this simulation using the CDF of the laboratory-measured saturated hydraulic conductivities. This case represents a single stochastic realization of a random hydraulic conductivity field.

From the water content changes shown in Figure 5.8 , it is apparent that the use of the random hydraulic conductivity field generates more realistic simulation results relative to the uniform Case 1 simulation. Comparison of 

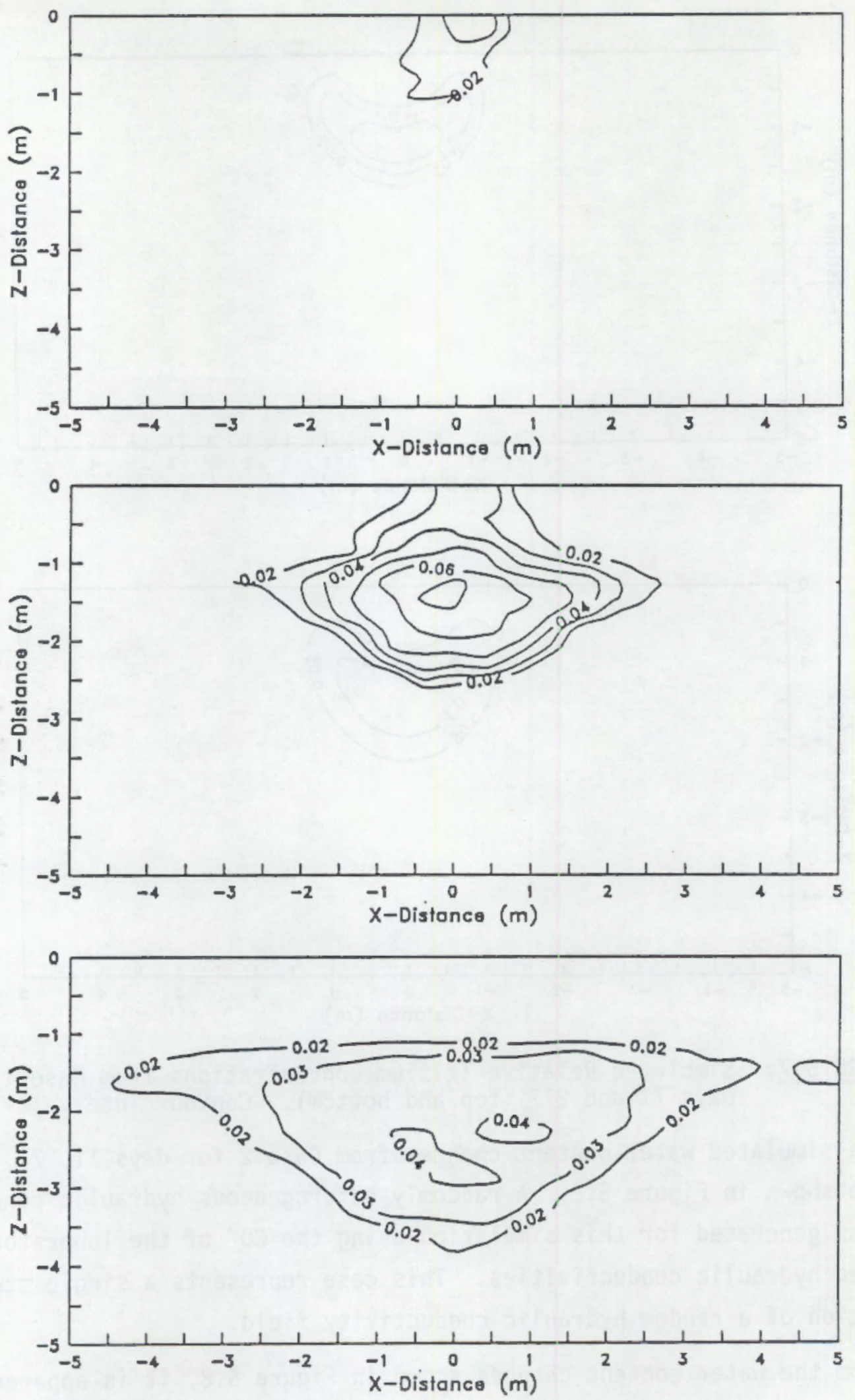

FIGURE 5.8. Simulated Water Content Changes from Case 2 for Days 11,71 and 277 (top to bottom). Contour interval $=0.01 \mathrm{~m}^{3} / \mathrm{m}^{3}$. 
Figure 5.8 with the observed water content changes from transect 2 (see Figure 5.3) indicates that the shape and distribution of the simulated water plume is somewhat closer to the observed data than the results from Case 1. The simulated water plume from the Case 2 simulation for day 277 also extends approximately $0.3 \mathrm{~m}$ deeper and slightly farther laterally than the observed water plume measured from transect 2.

The simulated relative concentrations of tritium from Case 2 for days 71 and 277 are shown in Figure 5.9. Like the water plumes, the solute plumes from the Case 2 simulation are irregular and somewhat closer in shape to the observed data (relative to Case 1). Again, the solute front lags behind the water front as the initial water in the profile is displaced. The observed relative concentration data also show a much higher peak concentration than the results from Case 2 .

The water content changes from Case 3 for days 11, 71, and 277 are shown in Figure 5.10. As described previously, the hydraulic properties were modified for Case 3 so that tensions corresponding to depth-averaged initial water contents from transect 2 could be used to more accurately represent the initial conditions of the experiment. In addition, the mixed form of the flow equation with a modified Picard iteration method was used rather than the head-based form of the flow equation with the standard Picard iteration method that is currently employed in PORFLO-3.

The simulated water content distributions for Cases 1 and 2 are considerably different from those for Case 3 . These differences can be primarily attributed to the more accurate representation of initial conditions and the revised hydraulic properties used for Case 3. Differences may be related also to the improved mass balance that was obtained using the modified Picard jteration method for Case 3.

The average cumulative mass balance error for the 277-day simulations, using the standard Picard iteration method, was $6.3 \%$ of the water mass added. Perfect mass balance (within machine precision) was obtained using the modified Picard iteration method for Case 3. The initial tensions used for the Case 3 simulation were also much higher than those used for the other cases. Therefore, perfect mass balance was obtained with the revised iteration method for an even more difficult problem (relative to Cases 1 and 2). 

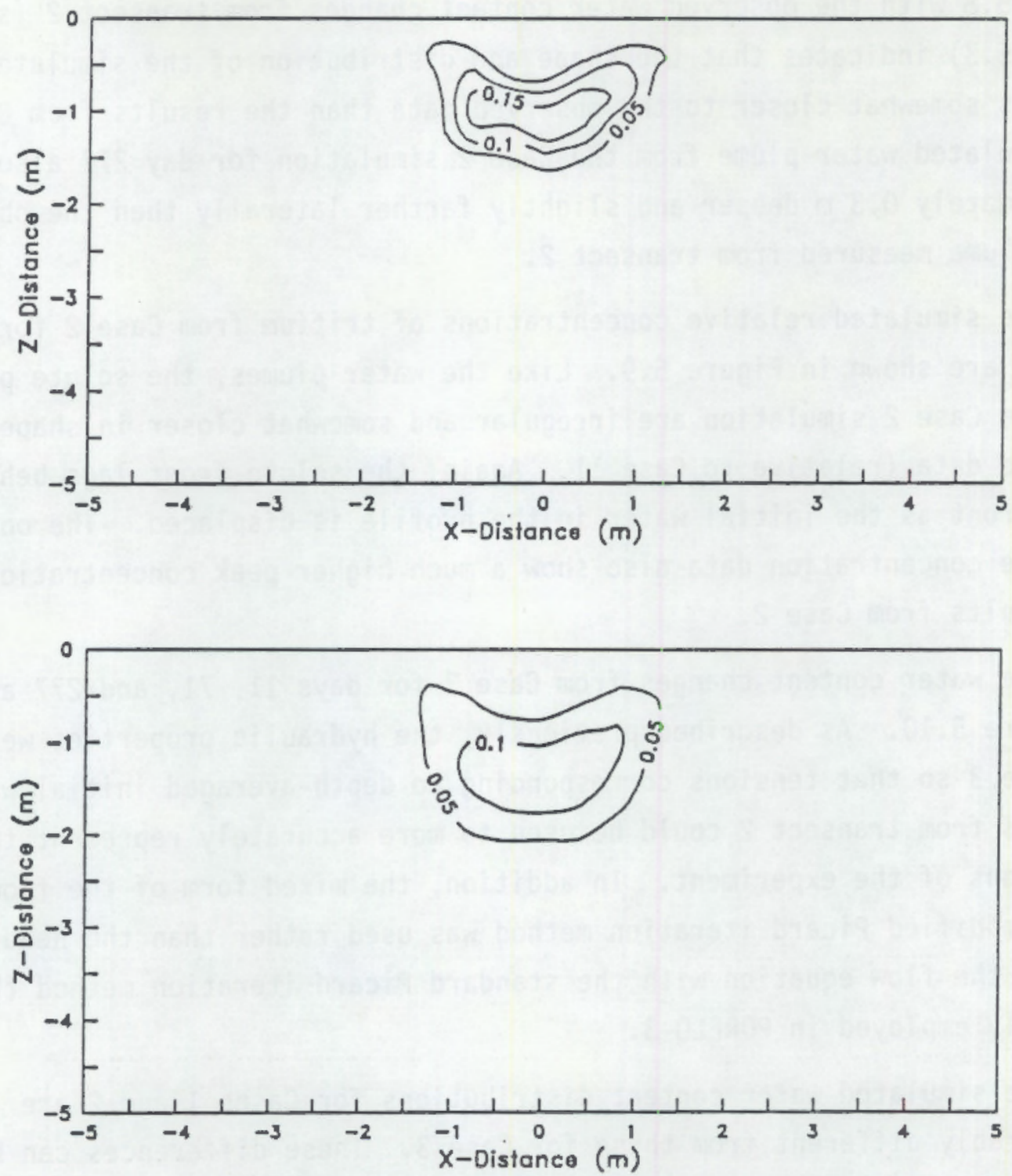

FIGURE 5.9. Simulated Relative Tritium Concentrations from Case 2 for Days 71 and 277 (top and bottom). Contour interval $=0.05$.

An upstream weighting scheme was used to calculate internodal hydraulic conductivites for all three simulation cases. Upstream weighting was used because it resulted in simulated wetting fronts that were closer to the observed wetting fronts during the infiltration phase of the simulations, relative to using a geometric mean weighting option. Work by Brutsaert (1971) has shown that in the case of sharp wetting fronts advancing into initially dry soils, it is often necessary to use the relative hydraulic conductivity for the element 

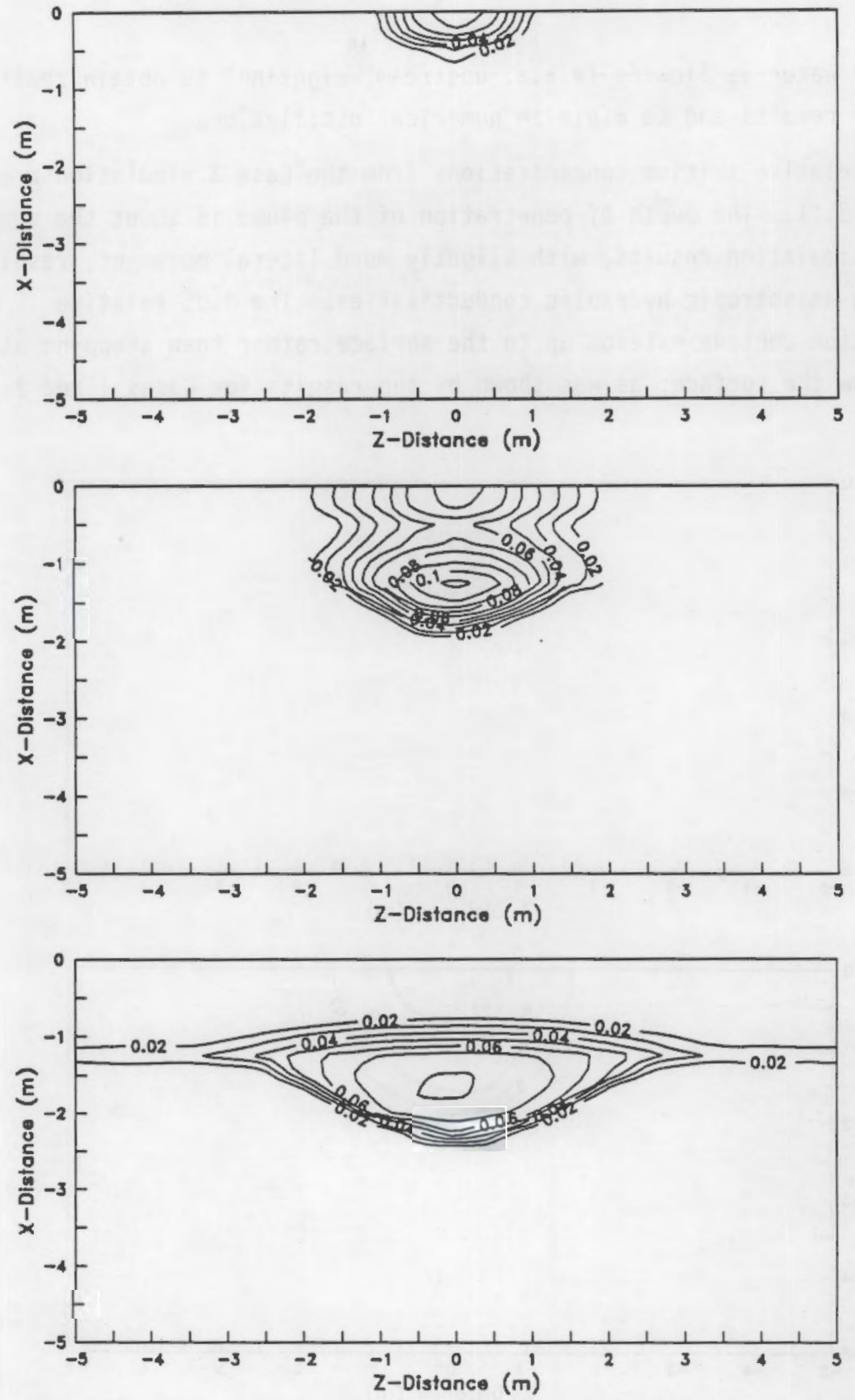

FIGURE 5.10. Simulated Water Content Changes from Case 3 for Days 11, 71, and 277 (top to bottom). Contour interval $=0.01 \mathrm{~m}^{3} / \mathrm{m}^{3}$. 
from which water is flowing (a.k.a. upstream weighting) to obtain realistic simulation results and to minimize numerical oscillations.

The relative tritium concentrations from the Case 3 simulation are shown in Figure 5.11. The depth of penetration of the plume is about the same as previous simulation results, with slightly more lateral movement, resulting from using anisotropic hydraulic conductivities. The 0.05 relative concentration contour extends up to the surface rather than stopping at about $0.2 \mathrm{~m}$ below the surface, as was shown by the results for Cases 1 and 2 .
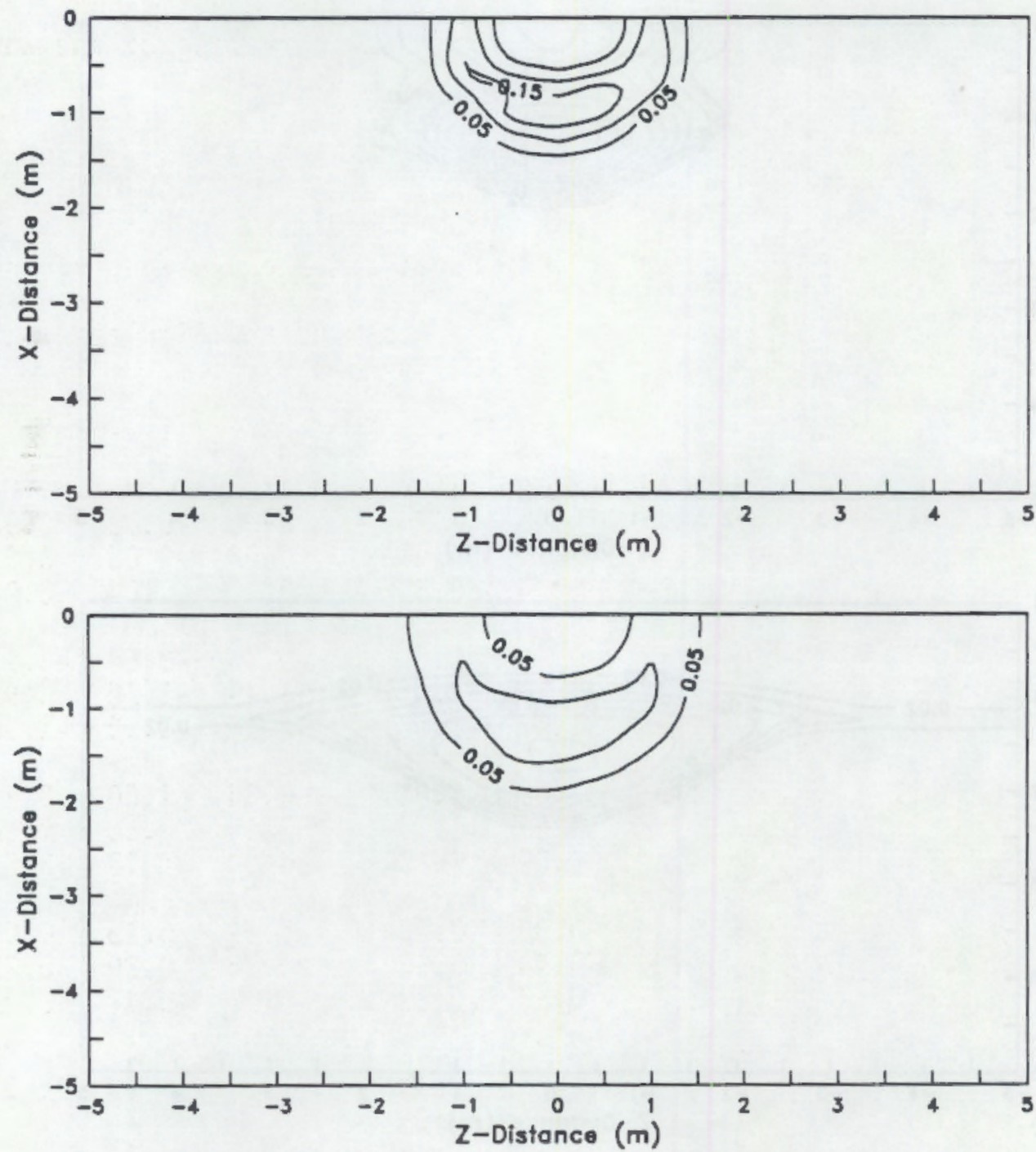

FIGURE 5.11. Simulated Relative Tritium Concentrations from Case 3 for Days 71 and 277 (top and bottom). Contour interval $=0.05$. 
The differences in transport results may be related to the improved mass balance, different initial conditions, and/or different hydraulic properties used for the case 3 simulation.

The results of the three cases and the field observations are summarized in Table 5.1 in terms of the first and second spatial moments. As previously described, the first moments define the center of mass in the $x$ - and $z$-directions. The second moments about the center of mass define a spatial covariance tensor. The components of this spatial covariance tensor are physically related to the spread of the water or solute plume about its center of mass. The $z$-coordinate of the center of mass and the $x$-variance are measures of the depth of penetration and horizontal spreading of the water plume, respectively.

As noted previously, because of the apparent edge effects and threedimensional flow in the experiment, it is probably most appropriate to compare simulation results to observations from transect 2 . The averages of the spatial

IABLE 5.1. Normalized Spatial Moments of Observed and Simulated Water Plumes on Days 11, 71, and 277

\begin{tabular}{|c|c|c|c|c|c|c|c|c|c|}
\hline \multirow{2}{*}{\multicolumn{2}{|c|}{$\begin{array}{l}\text { Spatial } \\
\text { Moments (a) }\end{array}$}} & \multirow{3}{*}{$\begin{array}{r}\text { Day } \\
\begin{array}{r}11 \\
71 \\
277\end{array}\end{array}$} & \multicolumn{4}{|c|}{ Observed (b) } & \multicolumn{3}{|c|}{ Simulated (c) } \\
\hline & & & 1 & 2 & 3 & Average & 1 & 2 & 3 \\
\hline$M_{10}$ & (m) & & $\begin{array}{l}1.11 \\
0.39 \\
1.57\end{array}$ & $\begin{array}{r}0.23 \\
0.04 \\
-0.12\end{array}$ & $\begin{array}{r}0.03 \\
-0.21 \\
0.14\end{array}$ & $\begin{array}{l}0.46 \\
0.07\end{array}$ & $\begin{array}{l}0.00 \\
0.00 \\
0.00\end{array}$ & $\begin{array}{l}-0.05 \\
-0.05 \\
-0.04\end{array}$ & $\begin{array}{r}0.00 \\
0.00 \\
-0.04\end{array}$ \\
\hline $\mathrm{M}_{01}(\mathrm{~d})$ & $(m)$ & $\begin{array}{r}11 \\
71 \\
277\end{array}$ & $\begin{array}{l}-0.43 \\
-1.35 \\
-1.83\end{array}$ & $\begin{array}{l}-0.77 \\
-1.38 \\
-1.79\end{array}$ & $\begin{array}{l}-0.46 \\
-1.10 \\
-1.42\end{array}$ & $\begin{array}{l}-0 . \\
-1 \\
-1\end{array}$ & $\begin{array}{l}-0.56 \\
-1.44 \\
-2.18\end{array}$ & $\begin{array}{l}-0.64 \\
-1.36 \\
-2.12\end{array}$ & $\begin{array}{l}-0.18 \\
-0.84 \\
-1.38\end{array}$ \\
\hline $\mathrm{M}_{20}$ & $\left(m^{2}\right)$ & $\begin{array}{r}11 \\
71 \\
277\end{array}$ & $\begin{array}{l}2.67 \\
1.39 \\
3.80\end{array}$ & $\begin{array}{l}1.05 \\
2.33 \\
4.44\end{array}$ & $\begin{array}{l}2.02 \\
1.58 \\
4.05\end{array}$ & $\begin{array}{l}1.9 \\
1.7 \\
4.1\end{array}$ & $\begin{array}{l}0.24 \\
2.16 \\
4.04\end{array}$ & $\begin{array}{l}1.50 \\
2.56 \\
4.13\end{array}$ & $\begin{array}{l}0.26 \\
1.50 \\
3.06\end{array}$ \\
\hline $\mathrm{M}_{02}$ & $\left(m^{2}\right)$ & $\begin{array}{r}11 \\
71 \\
277\end{array}$ & $\begin{array}{l}0.09 \\
0.66 \\
0.95\end{array}$ & $\begin{array}{l}0.43 \\
0.46 \\
0.72\end{array}$ & $\begin{array}{l}0.09 \\
0.44 \\
0.80\end{array}$ & $\begin{array}{l}0.20 \\
0.52 \\
0.82\end{array}$ & $\begin{array}{l}0.14 \\
0.36 \\
0.51\end{array}$ & $\begin{array}{l}0.15 \\
0.30 \\
0.47\end{array}$ & $\begin{array}{l}0.04 \\
0.28 \\
0.21\end{array}$ \\
\hline
\end{tabular}

(a) $M_{10}$ and $M_{01}$ are the $x-$ and $z$-coordinates of the center of mass. $\mathrm{M}_{20}$ and $\mathrm{M}_{02}$ are the $\mathrm{x}$ - and $\mathrm{z}$-variances.

(b) 1,2 , and 3 refer to neutron probe transects 1,2 , and 3 .

(c) 1,2, and 3 refer to simulation Cases 1,2, and 3 .

(d) Reflects the convention used for modeling, where $z$ is measured as negative downward, with the soil surface at $z=0 \mathrm{~m}$. 
moments from the three transects are listed in Table 5.1, as well as the spatial moments from each transect, to quantify the variability of the observations.

From the moments listed in Table 5.1, it is evident that the depth of penetration and horizontal spreading of the simulated water plume for Case 2 match the observed data from transect 2 relatively well. However, as depicted in Figures 5.3 and 5.8 , the simulated water content changes are 0.02 to $0.04 \mathrm{~m}^{3} / \mathrm{m}^{3}$ lower than the observed water content changes at specific spatial locations. This is the result of not accurately representing the initial water contents of the experiment in the case 2 simulation.

The spatial moments of the simulated water content changes for Case 3 indicate that this simulation does not match the observed data as well as Case 2. However, at specific spatial locations, the magnitude of the simulated water content changes for case 3 match the observed data better. This is the result of adjusting the water retention curve parameters so that the injtial water contents could be represented more accurately.

In an attempt to make the simulated depth of infiltration of the water plume match the observed data better, the lower half of the COF of the saturated hydraulic conductivities was truncated for Case 3 to increase the mean effective hydraulic conductivity. In addition, anisotropic hydraulic conductivities were used, with $\mathrm{K}_{\mathrm{x}}=1.5 \mathrm{~K}_{\mathrm{z}}$, to match the horizontal spread of the plume. The larger hydraulic conductivities obtained using the truncated distribution resulted in too much lateral spreading of the water plume during the redistribution phase of the simulation. This lateral spreading could be reduced by modifying the anisotropy ratio. A geometric mean option was used for calculating internodal hydraulic conductivites during the redistribution phase of the simulation for Case 3 .

In terms of predicting the mean flow behavior for the experiment, the uncalibrated model used for Case 2 performed better than the model used for Case 3. However, in terms of predicting the magnitude of the water content changes at specific spatial locations in the upper profile, the partially calibrated model used for Case 3 performed better than the uncalibrated model.

The results from these simulations suggest that further calibration of the model would be required to optimize the match between the simulated and observed 
results. This work also suggests that the spatial correlation structure of soil hydraulic properties should be considered in future simulations of the Las Cruces trench experiments.

Considerable effort was expended in attempting to reduce mass balance errors for the first two simulation cases. Various node spacings and time steps were tested with different convergence criteria in an attempt to minimize the mass balance error within a reasonable amount of computer time. The results of the simulations reported here were obtained with a convergence criterion specified as a value of less than 5.0E-9 for the maximum residual of any node in the active computational domain for both the flow and transport equations. These convergence criteria must be evaluated based on the units (meters) that were used for the simulations. It should also be recognized that the mass balance error could have been reduced further by taking smaller time steps and/or by reducing the node spacing. However, this would have been much more expensive computationally.

No mass balance checks are explicitly made in either version 1.0 or Version 1.1 of PORFLO-3. An alternative convergence criterion, listed in the PORFL0-3 Version 1.0 users manual (Runchal and Sagar 1989), is to specify the maximum allowable value of the sum of the residuals taken over all internal grid nodes. The code also has a provision that allows the user to specify flux balance calculations to be made, but these were found to be inadequate for evaluating the actual mass balance of the numerical solution. Therefore, a separate mass balance algorithm had to be written to evaluate simulation results.

The perfect water mass balance obtained using the modified Picard iteration method may have significant practical implications. The solution of the transport equation is linked to the solution of the flow equation through the dependence on the water content distribution and velocity field. Therefore, if the mass balance of the solution to the flow equation is poor, simulated solute or contaminant concentrations are likely to be in error. The magnitude and significance of this error are problem specific. However, for unsaturated flow problems, the magnitude of the mass balance error associated with the solution to the transport equation will likely be greater than or equal to the mass balance error associated with the solution to the flow equation. 
. 


\subsection{CONCLUSIONS}

Data from a field-scale, unsaturated zone flow and transport experiment, conducted at the Las Cruces trench site, were used to test the ability of the PORFLO-3 computer code to simulate water infiltration and solute transport in dry soils. A spatial moment analysis was used to provide a quantitative basis for comparing mean simulated and observed flow behavior.

Two-dimensional simulations produced water content changes that matched the observed data reasonably well. Models that explicitly incorporated heterogeneous hydraulic conductivity fields, generated from the cumulative probability distribution of the measured data, reproduced the characteristics of the observed data more closely than a uniform, homogeneous model. Improved point-wise predictions of water content changes were obtained by adjusting the soil hydraulic properties (i.e., calibrating the model).

Only fair agreement between the simulated and observed solute concentrations was obtained. Although the field experiment was specifically designed to create a two-dimensional flow regime, underprediction of the observed peak tritium concentrations appeared to be the result of three-dimensional flow and edge effects that resulted from natural soil heterogeneity and from the solution samplers being too close to the face of the trench.

The initially dry conditions that were used for these simulations provided a rigorous test of the ability of PORFLO-3 to simulate highly nonlinear, unsaturated flow problems. A significant finding of this work was the relatively poor mass balance that was obtained using the head-based form of the flow equation with the standard picard iteration method that is employed in the PORFLO-3 computer code. This poor mass balance motivated the development of a new version of the code.

A mixed form of the flow equation with a modified Picard iteration method (Celia et al. 1990) was incorporated into the new version of the code. This formulation reduced the cumulative mass balance error for the 277-day simulations, from an average of $6.3 \%$ of the water mass added, to within machine precision (or effectively perfect mass balance), with no more computational effort. This improved mass balance may have significant practical implications for future vadose zone transport modeling studies using the PORFLO-3 code. 
Considering the lack of spatial resolution of the solute concentration data and apparent edge effects, this experiment did not serve as a rigorous validation test of the transport simulation capabilities of the PORFLO-3 code. In addition, certain aspects of the site were ignored in the model simulations, such as the spatial correlation of soil hydraulic properties. Therefore, this study should only be considered a qualitative validation of the PORFLO-3 code. Applications of the code for waste management and remediation activities will require site-specific data for model calibration. 


\subsection{REFERENCES}

Barry, 0. A., and G. Sposito. 1990. "Three-Dimensional Statistical Moment Analys is of the Stanford/Waterloo Borden Tracer Test." Water Resour. Res. $26(8): 1735-1747$.

Brutsaert, W. A. 1971. "A Functional Iteration Technique for Solving the Richards Equation Applied to Two Dimensional Infiltration Problems." Water Resour. Res. $7(6): 1583-1596$.

Celia, M. A., E. T. Bouloutas, and R. L. Zarba. 1990. "A General MassConservative Numerical Solution for the Unsaturated Flow Equation." Water Resour. Res. 26(7):1483-1496.

Elabd, H., I. Porro, and P. J. Wierenga. 1988. "Estimation of Field Transport Parameters Using the Convection-Dispersion Equation." In Proc. Int. Conf. Validation of Flow and Transport Models for the Unsaturated Zone, Ruidoso, New Mexico, May 23-26, 1988.

Freyberg, D. L. 1986. "A Natural Gradient Experiment on Solute Transport in a Sand Aquifer: 2. Spatial Moments and the Advection and Dispersion of Nonreactive Tracers." Water Resour. Res. 22(13):2031-2046.

Gee, G. W., and J.W. Bauder. 1986. Particle-Size Analys is. In Methods of Soil Analysis, Part 1, Physical and Mineralogical Methods, Second Edition, A. Klute, ed. American Society of Agronomy, Inc and Soil Science Society of America, Inc., Madison, Wisconsin, pp. 9:383-411.

Jacobson, E. A. 1990. "Investigation of the Spatial Correlation of Saturated Hydraulic Conductivities from a Vertical Wall of a Trench." In Proc. of the Canadian/American Conference on Hydrogeology, Calgary, Alberta, September 1820,1990 .

Journel, A. G., and Ch. J. Huijbregts. 1978. Mining Geostatistics. Academic Press Inc., New York.

Magnusen, S. O., R. G. Baca, and A. J. Sondrup. 1990. Independent Verification and Benchmark Testing of the PORFL0-3 Computer Code, Version 1.0. EGG-BG-9175, Idaho National Engineering Laboratory, Idaho Falls, Idaho.

Mantoglou, A., and L. W. Gelhar. 1987. "Stochastic Modeling of Large-Scale Transient Unsaturated Flow Systems." Water Resour. Res. 23(1):37-46.

Mood, A. M., F. A. Graybill, and D. C. Boes. 1974. Introduction to the Theory of Statistics. Third Edition, McGraw-Hill Book Co., New York. 
Nicholson, T. J., P. J. Wierenga, G. W. Gee, E. A. Jacobson, D. J. Polmann, D. B. McLaughlin, and L. W. Gelhar. 1989. "Validation of Stochastic Flow and Transport Models for Unsaturated Soils: Field Study and Preliminary Results." In Proc. of the Conf. on Geostatistical, Sensitivity, and Uncertainty Methods for Ground-Water Flow and Radionuclide Transport Modeling, San Francisco, California, September 15-17, 1987, Battelle Press, Columbus, Ohio.

Nielsen, D. R., M. Th. van Genuchten, and J. W. Biggar. 1986. "Water Flow and Solute Transport Processes in the Unsaturated Zone." Water Resour. Res. $22(9): 895-1085$.

Patankar, S. V. 1980. Numerical Heat Transfer and Fluid Flow. Hemisphere Publishing Corporation, New York.

Polmann, D. J., E. G. Vomyoris, D. McLaughlin, E. M. Hammick, and L. W. Geihar. 1988. Application of Stochastic Methods to the Simulation of Large-Scale Unsaturated Flow and Transport. NUREG/CR-5094, U.S. Nuclear Regulatory Cominission, Washington, D.C.

Runchal, A. K., and 8. Sagar. 1989. PORFL0-3: A Mathematical Model for Fluid Flow, Heat, and Mass Transport in Variably Saturated Geologic Media Users Manual, Version 1.0. WHC-EP-0041, Westinghouse Hanford Company, Richland, Washington.

Sagar, B., and A. K. Runchal. 1990. PORFL0-3: A Mathematical Model for Fluid Flow, Heat, and Mass Transport in Variably Saturated Geologic Media Theory and Numerical Methods, Version 1.0. WHC-EP-0042, Westinghouse Hanford Company, Richland, Washington.

SURFER, Version 4, 1990. Golden Software, Inc., Golden, Colorado.

Tompson, A. F. B., R. Ababou, and L. W. Gelhar. 1987. Application and Use of the Three-Dimensional Turning Bands Random Field Generator: Single Realization Problems. Report No. 313, Ralph M. Parsons Laboratory, Massachusetts Institute of Technology, Cambridge, Massachusetts.

van Genuchten, M. Th. 1980. "A Closed-Form Equation for Predicting the Hydraulic Conductivity of Unsaturated Soils." Soil Sci. Soc. Am. J. $44(5): 892-898$.

Wierenga, P. J. 1988. "Validation of Flow and Transport Models at the Jornada Test Facility." In Validation of Flow and Iransport Models for the Unsaturated Zone: Conference Proceedings, P. J. Wierenga and 0 . Bachelet, eds. Research Report 88-55-04, New Mexico State University, Las Cruces, New Mexico.

Wierenga, P. J., A. F. Toorman, D. B. Hudson, J. Vinson, M. Nash, and R. G. Hills. 1989. Soil Physical Properties at the Las Cruces Trench Site. NUREG/CR-5441, U.S, Nuclear Regulatory Commission, Washington, D.C.

Wierenga, P. J., D. B. Hudson, R. G. Hills, I. Porro, M. R. Kirkland, and J. Vinson. 1990. Flow and Transport at the Las Cruces Trench Site, Experiments 1 and 2. NUREG/CR-5607, U.S. Nuclear Regulatory Commission, Washington, O.C. 
APPENDIX

THE STANDARD AND MODIFIED PICARD ITERATION METHODS 
APPENDIX

THE STANDARD AND MODIFIED PICARD ITERATION METHODS

The following notes, comparing the standard and modified Picard iteration methods, were taken from a workshop on unsaturated flow modeling, presented by the Massachusetts Institute of Technology (Gelhar et al. 1989). Additional information is incorporated from notes obtained at a Princeton University short course on unsaturated flow modeling (Celia et al. 1990a). The iteration methods are described in detail by Celia et al. (1990b).

\section{A.1 STANDARD PICARD ITERATION}

- Governing equation

$$
\begin{gathered}
C(h) \frac{\partial h}{\partial t}-\not \subset \cdot K(h) \not h-\frac{\partial K}{\partial z}=0 \\
C(h) \equiv \frac{d \theta}{d h}
\end{gathered}
$$

- Backward difference in time

$$
c^{n+1, m} \frac{h^{n+1, m+1}-h^{n}}{\Delta t}-\eta \cdot k^{n+1, m} \not h^{n+1, m+1}-\frac{\partial k^{n+1, m}}{\partial z}=0
$$

or

$$
\begin{aligned}
& \left.\frac{d \theta}{\partial h}\right|^{n+1, m}\left(h^{n+1, m+1}-h^{n+1, m}\right)-(\Delta t) \frac{\partial}{\partial x}\left[k^{n+1, m} \frac{\partial}{\partial x}\left(h^{n+1, m+1}-h^{n+1, m}\right)\right] \\
& =(\Delta t)\left\{\frac{\partial}{\partial x}\left[k^{n+1, m} \frac{\partial h^{n+1, m}}{\partial x}\right]+\frac{\partial k^{n+1, m}}{\partial z}-\left.\frac{d \theta}{d h}\right|^{n+1, m}\left(\frac{h^{n+1, m}-h^{n}}{\Delta t}\right)\right\} \\
& =(\Delta t) R^{n+1, m}
\end{aligned}
$$


where $\frac{d \theta}{d h}=$ specific moisture capacity

$K=$ hydraulic conductivity

$h=$ pressure head

$\theta=$ volumetric water content

$x=$ horizontal coordinate

$z=$ vertical coordinate

$t=$ time

$R=$ residual error

$n=$ time level

$m=$ iteration level

$\nabla=$ gradient operator .

\section{A.2 MODIFIED PICARD ITERATION}

- Governing equation

$$
\frac{\partial \theta}{\partial t}-\not \cdot K(h) \not h-\frac{\partial K}{\partial z}=0
$$

- Treatment of nonlinearities

1. Backward difference in time

$$
\frac{\theta^{n+1}-\theta^{n}}{\Delta \bar{t}} \cdot \frac{\partial}{\partial x}\left[K\left(h^{n+1}\right) \frac{\partial h^{n+1}}{\partial x}\right]-\frac{\partial K\left(h^{n+1}\right)}{\partial z}=0
$$

2. Iteration

$$
\frac{\theta^{n+1, m+1}-\theta^{n}}{\Delta t}-\frac{\partial}{\partial x}\left[K\left(h^{n+1, m}\right) \frac{\partial h^{n+1, m+1}}{\partial x}\right]-\frac{\partial K\left(h^{n+1, m}\right)}{\partial z}=0
$$




$$
\begin{aligned}
& \theta^{n+1, m+1} \simeq \theta^{n+1, m}+\left.\frac{d \theta}{d h}\right|^{n+1, m}\left(h^{n+1, m+1}-h^{n+1, m}\right) \\
& h^{n+1, m+1}=h^{n+1, m}+\left(h^{n+1, m+1}-h^{n+1, m}\right) \\
& \delta h^{m+1} \equiv h^{n+1, m+1}-h^{n+1, m} \\
& \frac{\theta^{n+1, m}+\left.\frac{d \theta}{d h}\right|^{n+1, m} \delta h^{m+1}-\theta^{n}}{\Delta t}-\frac{\partial}{\partial x}\left[x^{n+1, m} \frac{\partial}{\partial x}\left(h^{n+1, m}+\delta h^{m+1}\right)\right] \\
& -\frac{\partial K^{n+1, m}}{\partial z}=0 \\
& \left.\frac{d \theta}{d h}\right|^{n+1, m} \delta h^{m+1}-(\Delta t) \frac{\partial}{\partial x}\left[k^{n+1, m} \frac{\partial\left(\delta h^{m+1}\right)}{\partial x}\right] \\
& =(\Delta t)\left\{\frac{\partial}{\partial x}\left[x^{n+1, m} \frac{\partial h^{n+1, m}}{\partial x}\right]+\frac{\partial x^{n+1, m}}{\partial z}-\frac{\theta^{n+1, m}-\theta^{n}}{\Delta t}\right\} \\
& =(\Delta t) R^{n+1, m}
\end{aligned}
$$

Comparing the standard and modified Picard iteration methods indicates that the terms on the left side of the solution matrix are identical for the pressure-head-based form and mixed form of Richards equation. The right side of the solution matrix differs by

$$
\frac{\theta^{n+1, m}-\theta^{n}}{\Delta t} \text { vs. }\left.\frac{d \theta}{d h}\right|^{n+1, m}\left(\frac{h^{n+1, m}-h^{n}}{\Delta t}\right)
$$

This difference guarantees mass conservation (numerically) in the modified Picard iteration method. The head-based formulation appears to be identical to the mixed formulation in the differential limit, but discrete approximations of it tend not to conserve mass. 
Attainment of mass balance using a modified Picard iteration method is not always sufficient to guarantee good numerical solutions for unsaturated flow problems. For finite-element approximations, it is also necessary to use diagonalized time (mass) matrices to prevent oscillatory solutions (Celia et al. 19g0b).

\section{A.3 REFERENCES}

Celia, M. A., L. A. Ferrand, and D. L. Rudolph. 1990a. Fundamentals of Unsaturated Zone Modeling. A short course presented by Princeton University, Water Resources Program, Princeton, New Jersey, July 30 - August 2, 1990.

Celia, M. A., E. T. Bouloutas, and R. L. Zarba. 1990b. "A General MassConservative Numerical Solution for the Unsaturated Flow Equation." Water Resour. Res. 26(7):1483-1496.

Gelhar, L. W., D. MCLaughlin, and M. A. Celia. 1989. NRC Workshop on Modeling Unsaturated Flow. Conducted for the U.S. Nuclear Regulatory Commission, Office of Research, by the Massachusetts Institute of Technology, Cambridge, Massachusetts, January 11-13, 1989. 


\section{DISTRIBUTION}

No. of

Copies

OFFSITE

12 DOE/Office of Scientific and Technical Information

5 U.S. Department of Energy 1000 Independence Ave. SW Forrestal Building Washington, DC 20585

ATTN: L. P. Duffy, EM-1

C. Frank, EM-50

S. Lien, EM-54

J. Lytle, EM-30

R. P. Whitfield, EM-40

3 U.S. Department of Energy

12800 Middle Brook Rd Germantown, MD 20874

ATTN: C. Cooley, EM-55

H. Barainca, EM-53

K. Hain, EM-54

T. J. Nicholson

U.S. Nuclear Regulatory Commission

Office of Nuclear Regulatory Research

5650 Nicholson Lane

Washington, DC 20852

3 Battelle Memorial Institute Project Management Division 505 King Avenue Columbus, $\mathrm{OH} 43201$

ATTN: H. A. Carbeiner

R. A. Nathan Technical Library

2 Desert Research Institute P.0. Box 60220

Reno, NV 89506

ATTN: E. A. Jacobson

S. Tyler
No. of

Copies

4 EG\&G, Inc.

2151 North Blvd.

Idaho Falls, ID 83415

ATTN: R. G. Baca

S. Magnuson

R. R. Seitz

J. B. Sisson

3 Lawrence Berkeley Laboratory

Earth Sciences Division

University of California

Berkeley, CA 94720

ATTN: K. Prues 5

C. F. Tsang

J. S. Wang

2 Sandia Laboratories

P.0. Box 5800

Albuquerque, NM 87185

ATTN: R. W. Lynch

Technical Library

2 University of Arizona

Department of Water Resources

Building 11

Tucson, AZ 87521

ATTN: N. J. Aimo

S. P. Neuman

G. S. Campbell

Agronomy Department

Washington State University

Pullman, WA 99164

D. Hillel

Department of Plant and Soil Science

12A Stockbridge Hall

University of Massachusetts

Amherst, MA 01003

R. G. Hills

Department of Mechanical Engineering

New Mexico State University

Las Cruces, NM 88003 
No. of

Copies

T. L. Jones

New Mexico State University

Department of Agronomy and Horticulture

Department 30

Las Cruces, NM 88003-0003

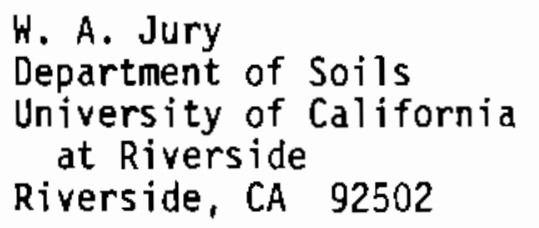

J. B. Kool

HydroGeoLogic, Inc.

503 Carlisle Drive, Suite 250

Herndon, VA 22070

B. Sagar

Southwest Research Institute

Division 20

6220 Culebra Road

P.0. Drawer 28510

San Antonio, TX 78228-0510

P. J. Wierenga

Dept. of Soil and Water Science

University of Arizona

Tucson, AZ 85721

\section{ONSITE}

13 DoE Richland Operations Office
G. J. Bracken
J. J. Broderick
C. E. Collantes
R. D. Freeburg
M. J. Furman
J. M. Hennig
J. R. Hunter
R. D. Izatt
S. K. Moy
0. L. 0lson
J. M. Peterson
G. W. Rosenwald
J. J. Sutey

No. of

Copies

13 Hestinghouse Hanford Company

M. R. Adams

L. C. Brown

J. W. Cammann

M. P. Connelly

J. D. Davis

K. R. Fecht

$R$. L. Jackson

R. Khaleel

R. E. Lerch

H. E. McGuire

S. J. Phillips

J. C. Sonnichsen

N. R. Wing

40 Pacific Northwest Laboratory

M. P. Bergeron

M. D. Campbel]

C. R. Cole

J. H. Falco

M. J. Fayer (2)

M. D. Freshley

G. W. Gee

M. J. Graham

J. M. Hales

P. C. Hays

D. J. Holford

C. T. Kincaid

J. F. Keller

R. R. Kirkham

E. M. Murphy

R. W. Nelson

W. E. Nichols

K. R. Roberson

M. L. Rockhold

R. J. Serne

C. S. Simmons

R. L. Skaggs

J. L. Smoot

D. L. Stewart

T. L. Stewart

G. P. Streile

S. K. Wurstner (2)

S. B. Yabusaki

Publishing Coordination

Technical Report Files (5) 